\title{
Cooperation between CYB5R3 and NOX4 via coenzyme Q mitigates endothelial inflammation
}

\author{
Shuai Yuan ${ }^{a}$, Scott A. Hahn ${ }^{\text {a }}$, Megan P. Miller ${ }^{\text {a }}$, Subramaniam Sanker ${ }^{a}$, Michael J. Calderon ${ }^{c}$, \\ Mara Sullivan $^{\text {c }}$, Atinuke M. Dosunmu-Ogunbi ${ }^{\text {a,b }}$, Marco Fazzari ${ }^{\text {b }}$, Yao Li ${ }^{\text {a }}$, Michael Reynolds ${ }^{\text {a }}$, \\ Katherine C. Wood ${ }^{\mathrm{a}}$, Claudette M. St Croix ${ }^{\mathrm{c}}$, Donna Stolz ${ }^{\mathrm{c}}$, Eugenia Cifuentes-Pagano ${ }^{\mathrm{a}, \mathrm{b}}$, \\ Placido Navas $^{\mathrm{d}}$, Sruti Shiva ${ }^{\mathrm{a}, \mathrm{b}}$, Francisco J. Schopfer ${ }^{\mathrm{a}, \mathrm{b}, \mathrm{e}}$, Patrick J. Pagano ${ }^{\mathrm{a}, \mathrm{b}}$, \\ Adam C. Straub a, b, f,
}

${ }^{a}$ Heart, Lung, Blood and Vascular Medicine Institute, University of Pittsburgh, Pittsburgh, PA, USA

${ }^{\mathrm{b}}$ Department of Pharmacology and Chemical Biology, University of Pittsburgh, Pittsburgh, PA, USA

${ }^{\mathrm{c}}$ Center for Biologic Imaging, University of Pittsburgh, Pittsburgh, PA, USA

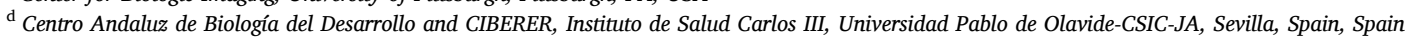

${ }^{\mathrm{e}}$ Pittsburgh Liver Research Center (PLRC), University of Pittsburgh, Pittsburgh, PA, USA

${ }^{\mathrm{f}}$ Center for Microvascular Research, University of Pittsburgh, Pittsburgh, PA, USA

\section{A R T I C L E I N F O}

\section{Keywords:}

CYB5R3

NOX4

$\mathrm{CoQ}$

ROS

Inflammation

\begin{abstract}
A B S T R A C T
NADPH oxidase 4 (NOX4) regulates endothelial inflammation by producing hydrogen peroxide $\left(\mathrm{H}_{2} \mathrm{O}_{2}\right)$ and to a lesser extent $\mathrm{O}_{2}{ }^{\bullet-}$. The ratio of NOX4-derived $\mathrm{H}_{2} \mathrm{O}_{2}$ and $\mathrm{O}_{2}{ }^{\bullet-}$ can be altered by coenzyme Q (CoQ) mimics. Therefore, we hypothesize that cytochrome $b 5$ reductase 3 (CYB5R3), a CoQ reductase abundant in vascular endothelial cells, regulates inflammatory activation. To examine endothelial CYB5R3 in vivo, we created tamoxifen-inducible endothelium-specific Cyb5r3 knockout mice (R3 KO). Radiotelemetry measurements of systolic blood pressure showed systemic hypotension in lipopolysaccharides (LPS) challenged mice, which was exacerbated in R3 KO mice. Meanwhile, LPS treatment caused greater endothelial dysfunction in R3 KO mice, evaluated by acetylcholine-induced vasodilation in the isolated aorta, accompanied by elevated mRNA expression of vascular adhesion molecule 1 (Vcam-1). Similarly, in cultured human aortic endothelial cells (HAEC), LPS and tumor necrosis factor $\alpha(\mathrm{TNF}-\alpha)$ induced VCAM-1 protein expression was enhanced by Cyb5r3 siRNA, which was ablated by silencing the Nox4 gene simultaneously. Moreover, super-resolution confocal microscopy indicated mitochondrial co-localization of CYB5R3 and NOX4 in HAECs. APEX2-based electron microscopy and proximity biotinylation also demonstrated CYB5R3's localization on the mitochondrial outer membrane and its interaction with NOX4, which was further confirmed by the proximity ligation assay. Notably, Cyb5r3 knockdown HAECs showed less total $\mathrm{H}_{2} \mathrm{O}_{2}$ but more mitochondrial $\mathrm{O}_{2}{ }^{\bullet-}$. Using inactive or non-membrane bound active CYB5R3, we found that CYB5R3 activity and membrane translocation are needed for optimal generation of $\mathrm{H}_{2} \mathrm{O}_{2}$ by NOX4. Lastly, cells lacking the CoQ synthesizing enzyme COQ6 showed decreased NOX4-derived $\mathrm{H}_{2} \mathrm{O}_{2}$, indicating a requirement for endogenous CoQ in NOX4 activity. In conclusion, CYB5R3 mitigates endothelial inflammatory activation by assisting in NOX4-dependent $\mathrm{H}_{2} \mathrm{O}_{2}$ generation via CoQ.
\end{abstract}

\section{Introduction}

In the vascular wall, the endothelium governs leukocyte recruitment during inflammation to help detain and remediate pathogens [1].
Pathogenic stimuli such as endotoxin activate endothelium to rapidly deploy adhesion molecules to the surface to entrap leukocytes and facilitate diapedesis [2]. Vascular cell and intercellular adhesion molecules, VCAM-1 and ICAM-1, are major endothelial recruitment factors for leukocytes at sites of infection [3-5]. In severe infection, endotoxin

\footnotetext{
* Corresponding author. Pharmacology and Chemical Biology Director of the Center for Microvascular Research University of Pittsburgh School of Medicine,

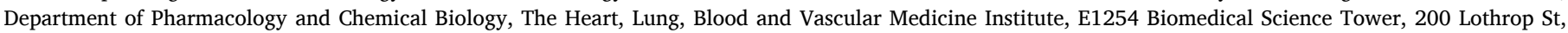
Pittsburgh, PA, 15216, USA.

E-mail address: astraub@pitt.edu (A.C. Straub).
} 


$\begin{array}{ll}\text { Abbreviations } \\ \text { CoQ } & \text { coenzyme Q } \\ \text { CYB5R3 } & \text { cytochrome } b 5 \text { reductase } 3 \\ \text { R3 } & \\ \text { GFP } & \text { green fluorescent protein } \\ \mathrm{H}_{2} \mathrm{O}_{2} & \text { hydrogen peroxide } \\ \mathrm{HAEC} & \text { human aortic endothelial cell } \\ \mathrm{HEK} & \text { human embryonic kidney cell } \\ \text { ICAM-1 } & \text { Intercellular cell adhesion molecule 1 } \\ \text { KO } & \text { knockout } \\ \text { LPS } & \text { lipopolysaccharides } \\ \text { NF- } \mathrm{kB} & \text { Nuclear factor kappa B } \\ \text { NO } & \text { nitric oxide } \\ \text { NOS2 } & \text { nitric oxide synthase 2, inducible } \\ \text { NOS3 } & \text { nitric oxide synthase 3, endothelial } \\ \text { NOX4 } & \text { NADPH oxidase } 4\end{array}$

NQO1 NAD(P)H quinone oxidoreductase 1

$\mathrm{O}_{2} \quad$ superoxide anion

PLA proximity ligation assay

siNOX4 Nox4 siRNA

siNT non-targeting siRNA

siR3 Cyb5r3 siRNA

TLR4 toll-like receptor 4

TNF- $\alpha$ tumor necrosis factor $\alpha$

TOM20 translocase of outer mitochondrial membrane 20

UQ ubiquinone

$\mathrm{UQH}^{\bullet} \quad$ semiubiquinone

VCAM-1 vascular cell adhesion molecule 1

WT wild-type

Protein names are abbreviated as capital letters (e.g., CYB5R3) while the corresponding gene names are annotated as in italic lower cases (e.g., Cyb5r3) released by circulating pathogens exacerbates this process, causing systemic hypotension, reduced peripheral blood flow, and multi-organ failure [6,7]. One important element of the inflammatory signaling response is reactive oxygen species. Reactive oxygen species are being increasingly appreciated for their essential role in cellular signal transduction and conditioning. On the one hand, phagosomal superoxide $\left(\mathrm{O}_{2}{ }^{\bullet-}\right)$ in leukocytes kills bacteria, whereas excessive reactive species such as $\mathrm{O}_{2}{ }^{\bullet-}$, hydrogen peroxide $\left(\mathrm{H}_{2} \mathrm{O}_{2}\right)$, and peroxynitrite can contribute to host endothelial overactivation and dysfunction $[8,9]$.

Endothelial cells employ a diversity of machinery, under physiological and pathological conditions, to generate reactive species such as $\mathrm{O}_{2}{ }^{-}$and $\mathrm{H}_{2} \mathrm{O}_{2}$. NADPH oxidases (NOX) are a family of enzymes dedicated to reducing ambient oxygen for $\mathrm{O}_{2}{ }^{\bullet-}$ and $\mathrm{H}_{2} \mathrm{O}_{2}$ formation. In the NOX family, NOX4 is unique on several levels: 1 ) it is constitutively activated, 2) it predominantly produces $\mathrm{H}_{2} \mathrm{O}_{2}$ versus $\mathrm{O}_{2}{ }^{\bullet-}$, 3) it is compartmentalized on intracellular membranes and in particular the mitochondrion and 4) it serves divergent roles in the cardiovascular system [10-12]. Although NOX4 is protective in animal models of chronic inflammation, including atherosclerosis and peripheral arterial disease $[13,14]$, it exacerbates the acute inflammatory response induced by lipopolysaccharides and tumor necrosis factor $\alpha$ (TNF- $\alpha)$ in endothelial cells [15-17]. However, it remains incompletely understood how NOX4 causes these opposing cardiovascular outcomes.

One explanation for NOX4's dichotomous functions in cardiovascular outcomes likely stems from its capacity to generate two different primary products, $\mathrm{H}_{2} \mathrm{O}_{2}$ and $\mathrm{O}_{2}{ }^{\bullet-}$. Coenzyme $\mathrm{Q}$ (CoQ) has been suggested to augment NOX4's production of $\mathrm{H}_{2} \mathrm{O}_{2}$, but the evidence is limited to biochemical studies using synthetic quinone compounds and a CoQ reductase, $\mathrm{NAD}(\mathrm{P}) \mathrm{H}$ quinone oxidoreductase 1 (NQO1) [18]. Ubiquitously synthesized by mammalian cells, CoQ has a long hydrophobic side chain embedded in the lipid bilayer and a benzoquinone head group. The head group is redox-sensitive and can receive or donate up to two electrons to cycle between three distinct states: the fully oxidized ubiquinone, the fully reduced ubiquinol, and the semiubiquinone radical. CoQ redox cycling allows it to shuttle electrons between enzymes maintaining their activity [19]. Therefore, endogenous CoQ may modulate NOX4 activity with the assistance of a CoQ reductase.

Cytochrome $b 5$ reductase 3 (CYB5R3) is a CoQ reductase highly expressed in endothelial cells. CYB5R3-dependent CoQ reduction is essential in the membrane antioxidation pathway [20-22]. In addition to CoQ reduction, CYB5R3 mediates the reduction of hemeproteins such as cytochrome $b 5$ and hemoglobin, which is required for fatty acid metabolism and the prevention of methemoglobinemia [23,24]. We have previously demonstrated that endothelial cells in small arteries and arterioles use CYB5R3 to modulate nitric oxide signaling via $\alpha$-globin heme redox cycling [25]. However, the role of endothelial cell CYB5R3 in large arteries, such as the aorta, has not been investigated. This constitutes a critical research gap since endothelial cells of large arteries abundantly express CYB5R3 but do not express $\alpha$-globin or use fatty acid as a primary source of energy. Therefore, considering the critical role of NOX4 in inflammation and the potential interaction between NOX4 and CYB5R3, we hypothesized that endothelial CYB5R3 regulates inflammatory activation by modulating NOX4 oxidant formation.

\section{Methods and materials}

\subsection{Animals}

All animal studies were approved by and in compliance with the University of Pittsburgh Institutional Animal Care and Use Committee. Cyb5r3 floxed mice $\left(C y b 5 r 3^{f / f l}\right)$ were generated as previously described [26]. Both wild-type C57BL/6J and Cyb5r $3^{f / f l}$ mice were crossed with the tamoxifen-inducible Cdh5(PAC)-CreERT2 mice kindly provided by Dr. Ralf Adams [27]. Male mice at the age of 10-12 weeks were treated with tamoxifen (10 mg/kg in corn oil) intraperitoneally for five consecutive days and allowed to rest for seven days before experiments. All mice were assigned a number randomly at birth, and the genotype was concealed from the technician during LPS treatment and data acquiring. All mice used in this study were reported.

\subsection{Cell culture}

Human aortic endothelial cells (HAEC) were purchased from Lonza and maintained in endothelial growth medium (EGM-2, Lonza, CC3162), with $5 \% \mathrm{CO}_{2}$, at $37{ }^{\circ} \mathrm{C}$. According to Lonza's suggestion, population doubling was used to track the age of cells in culture instead of the conventional passage number. Cells less than 13 times of population doublings were used for experiments. In an experiment, HAECs were allowed to grow fully confluent before they were challenged with LPS (1 or $10 \mu \mathrm{g} / \mathrm{ml}$ ) for indicated incubation time.

HEK293FT cells were obtained from Thermo Fisher Scientific (R70007) and grew in Dulbecco's Modified Eagle Medium (DMEM, 12430062) with $10 \%$ fetal bovine serum. COQ6 gene deletion was achieved in HEK293 cells with the CRISPR-Cas9 technology and kindly offered by Dr. Placido Navas [28]. The COQ6 knockout cell line and corresponding control cell line were maintained in DMEM with 10\% fetal bovine serum. Additionally, $10 \mu \mathrm{M}$ uridine was supplied for both cell lines to compensate for the loss of CoQ. 


\subsection{Cloning of expression vectors}

The wild-type (WT) human Cyb5r3 (NM_000398.6) was cloned from a pINCY vector (LIFESEQ1901142, Open Biosystems) into the pcDNA3.1 expression vector (Invitrogen, V86020). The nucleotides encoding the first 23 amino acids for membrane anchoring were deleted ( $\triangle \mathrm{AA} 1-23$ ) by PCR. Two inactive variants, K111A and K111A/G180V, were created by point mutations on the pcDNA3.1-Cyb5r3 (WT) plasmid using QuikChange II XL Site-Directed Mutagenesis Kit (Agilent, 200521). Mutagenesis primers were designed using Agilent's online program. Additionally, human Nox4 (AF254621.1) and p22 (NM_000101.4) in pcDNA3.1 were kindly provided by Dr. Patrick Pagano.

\subsection{In vitro transfection of siRNA and expression vectors}

The transfection of siRNA in HAECs and expression vectors in HEK293 cells were achieved using Lipofectamine 3000 (Thermo Fisher Scientific, L3000015) according to the manufacturer's instructions. Non-targeting siRNA (siNT) and human Cyb5r3 targeting siRNA (siR3) were purchased from Horizon Discovery (D-001810-01-20 and L009554-00-0005). Human Nox4 targeting siRNA was purchased from Invitrogen (Stealth siRNA, HSS121312). The day before transfection, HAECs were seeded at $15,000-20,000$ cells $/ \mathrm{cm}^{2}$ in 12 -well plates. For Cyb5r3 silencing alone, $10 \mu \mathrm{M}$ of siNT or siR3 was given to HAECs in lipid complex overnight, before the medium was replenished to allow cells to recover. The incubation duration was counted from the time of medium change. For experiments involving Cyb5r3 and Nox4 double knockdown, four groups of cells received $20 \mu \mathrm{M}$ siNT, $10 \mu \mathrm{M}$ siNT +10 $\mu \mathrm{M}$ siR3, $10 \mu \mathrm{M}$ siNT $+10 \mu \mathrm{M}$ siNox4, or $10 \mu \mathrm{M}$ siR3 $+10 \mu \mathrm{M}$ siNox4, respectively. In this way, siRNA loads were kept the same in all treatment groups.

HEK293(FT) cells were seeded at $80,000 \mathrm{cell} / \mathrm{cm}^{2}$ in 12 -well plates. Plasmids for NOX4, p22, and CYB5R3 WT were used at $0.3 \mu$ g per well. For unknown, CYB5R3 mutants showed different expression efficiency or protein stability. The amount of plasmid used per well was empirically adjusted as the following: K111A $0.15 \mu \mathrm{g}, \mathrm{K} 111 \mathrm{~A} / \mathrm{G} 180 \mathrm{~V} 0.2 \mu \mathrm{g}$, $\triangle \mathrm{AA1}-230.09 \mu \mathrm{g}$. When experiments were performed in different cell culture vessels, the plasmid amount is scaled according to the growth area.

Two days after the transfection of siRNA or expression vectors, HAECs were treated with LPS, and HEK293(FT) cells were collected for downstream analysis.

\subsection{APEX2 related electron microscopy and affinity pulldown}

Transient expression of CYB5R3-APEX2 was achieved by using lentivirus as described above. Our bicistronic vector coexpresses CYB5R3-APEX2 and green fluorescent protein (GFP) with an internal ribosome entry site (IRES). To avoid arbitrary effects due to a high level of expression, we used a low concentration of virus to obtain $10 \%$ GFP positive cells. APEX2 based electron microscopy and affinity enrichment were performed according to previous publications [29,30].

For electron microscopy, HAECs were fixed with $2 \%(\mathrm{v} / \mathrm{v})$ glutaraldehyde in $100 \mathrm{mM}$ cacodylate solution. Fixed cells were loaded with 0.5 $\mathrm{mg} / \mathrm{ml} \mathrm{3,3'-Diaminobenzidine} \mathrm{(DAB)} \mathrm{and} \mathrm{treated} \mathrm{with} 10 \mathrm{mM} \mathrm{H}_{2} \mathrm{O}_{2}$. Once brown precipitates form in CYB5R3-APEX2 positive cells, cells were rinsed with $100 \mathrm{mM}$ cacodylate solution, post-fixed in $1 \%$ osmium tetroxide with $1 \%$ potassium ferricyanide, rinsed in PBS, dehydrated through a graded series of ethanol, and embedded in Poly/Bed ${ }^{\circ} 812$ (Luft formulations). Semi-thin $(300 \mathrm{~nm})$ sections were cut on a Leica Reichart Ultracut, stained with $0.5 \%$ Toluidine Blue in $1 \%$ sodium borate, and examined under the light microscope. Ultrathin sections (65 $\mathrm{nm}$ ) were examined on a JEOL 1400 Plus transmission electron microscope with a side mount AMT 2k digital camera (Advanced Microscopy Techniques, Danvers, MA).

For affinity pulldown, HAECs were incubated with $500 \mu \mathrm{M}$ biotin- phenoxyl radical (Cayman, 26997) for $30 \mathrm{~min}$. To activate APEX2, $\mathrm{H}_{2} \mathrm{O}_{2}$ was added at the final concentration of $100 \mu \mathrm{M}$ for $60 \mathrm{~s}$. Biotinphenoxyl radical were immediately neutralized by repeated washing with the quench buffer ( $10 \mathrm{mM}$ sodium ascorbate, $10 \mathrm{mM}$ sodium azide, $5 \mathrm{mM}$ Trolox [Cayman, 10011659] in phosphate-buffered saline, $\mathrm{pH}$ 8). Biotinylated proteins were enriched using Dynabeads ${ }^{\mathrm{TM}} \mathrm{M}-280$ Streptavidin (Invitrogen, 11205D) and eluted by heating the beads in $2 \mathrm{X}$ Laemmli buffer for immunoblotting.

\subsection{Quantification of $\mathrm{H}_{2} \mathrm{O}_{2}$ and NOX4 activity}

Cellular production of $\mathrm{H}_{2} \mathrm{O}_{2}$ was evaluated by its fluorescent reaction product with coumarin boronic acid (Cayman, 14051) in the presence of L-NAME (Cayman, 80210) and taurine (Cayman, 27031) [31-33]. Coumarin boronic acid (CBA) is a sensitive probe for hydrogen peroxide, but necessary control must be included to rule out interference from peroxynitrite and hypochlorous acid. L-NAME inhibits NOS activity and therefore prevents peroxynitrite production, while taurine scavenges hypochlorous acid. Therefore, both L-NAME and taurine are added to the assay buffer to improve the probe's specificity [34]. For endothelial cells, cells were plated and transfected in a 96-well plate. To measure $\mathrm{H}_{2} \mathrm{O}_{2}$, the medium was changed to the assay buffer $(20 \mathrm{mM}$ HEPES $\mathrm{pH}$ 7.5, $10 \mu \mathrm{M}$ EDTA, $100 \mu \mathrm{M}$ L-NAME, $1 \mathrm{mM}$ taurine, and $0.01 \%$ bovine serum albumin in DMEM). For each group, negative controls were included by adding catalase to the final concentration of $500 \mu \mathrm{g} / \mathrm{ml}$. Reactions were started by adding $20 \mu \mathrm{M}$ CBA probe. Fluorescence $(350 / 450 \mathrm{~nm})$ was measured kinetically at $37^{\circ} \mathrm{C}$ for $4 \mathrm{~h}$. At the end of the assay, endothelial cells were stained with crystal violet to determine the number of cells. To calculate the reaction rate, the log phase slope was normalized with the crystal violet staining results. For HEK293(FT) cells, since they did not withstand repeated rinsing during crystal violet staining, a different strategy was used for normalization. After transfection, HEK293(FT) cells were dislodged, counted, and resuspended in the assay buffer so that each well in a 96-well plate contains 120,000 cells at the time of the assay. Otherwise, the CBA assay was performed the same as for HAECs. Additionally, cells were pelleted from the remaining cell suspension for protein quantification to normalize the result. Importantly, for each treatment, the fluorescent signal from a corresponding catalase control was included, and the catalase-inhibitable amount was designated as $\mathrm{H}_{2} \mathrm{O}_{2}$. The CBA probe is membrane permeable, while catalase is not. Therefore, the catalase-inhibitable signal represents extracellular $\mathrm{H}_{2} \mathrm{O}_{2}$ concentration, which correlates with its intracellular level.

\subsection{Mitochondrial $\mathrm{O}_{2}{ }^{\bullet-}$ measurement}

Cells were transfected in 10-cm dishes for siRNA transfection. To measure mitochondrial $\mathrm{O}_{2}{ }^{\circ-}$, cells were trypsinized and resuspended in $\mathrm{Ca}^{2+}$ and $\mathrm{Mg}^{2+}$ negative Hank's balanced salt solution (HBSS). In a 96well plate, 100,000 cells were added to each well with $5 \mu \mathrm{M}$ MitoSOX ${ }^{\mathrm{TM}}$ Red (Invitrogen, M36008). Immediately after the addition of MitoSOX, the fluorescent signal $(510 / 580 \mathrm{~nm})$ was recorded at $37{ }^{\circ} \mathrm{C}$ for $2 \mathrm{~h}$. To reduce variation, fluorescent intensities within every 5 min were averaged before the log phase slope was calculated to represent the reaction rate. The results were normalized with the protein concentrations measured in the remaining cell suspension.

\subsection{Statistics}

Data were reported as mean \pm standard error of the mean unless specified otherwise. The $\mathrm{n}$ value represents the number of animals or independent experiments repeated on different days. Statistical analysis was performed with Graph Pad Prism 8 using Student t-test, one-way ANOVA, and two-way ANOVA with Sidak or Tukey post-hoc test. Pvalues less than 0.05 were considered as statistically significant. Specific tests used for experiments are shown in figure legends. 
Extended methods can be found in the supplementary material.

\section{Results}

\subsection{Endothelial CYB5R3 protects against LPS-induced inflammatory responses in vivo}

Cyb5r3 floxed mice were previously generated by our group and crossed with Cdh5-CreER ${ }^{T 2}$ mice to create the tamoxifen-inducible, endothelium-specific Cyb5r3 knockout mice (R3 KO) [26] (Fig. 1a). After five consecutive days of intraperitoneal tamoxifen injections (10 $\mathrm{mg} / \mathrm{kg}$ ), endothelial CYB5R3 protein was absent in the aorta from R3 KO mice (Fig. 1a). To determine whether endothelial CYB5R3 affects LPS induced systemic hypotension, we implanted radiotelemetry units in mice to monitor real-time changes in arterial blood pressure. At baseline, there was no difference in resting blood systolic pressure between R3 KO mice and WT controls during a full 24-h cycle (Fig. 1b). However, significantly lower heart rates were observed in the R3 KO mice (Supplementary Table 1). A single sublethal dose of LPS ( $5 \mathrm{mg} / \mathrm{kg}$ ) injected intraperitoneally caused a drop in systolic blood pressure in WT (Fig. 1c). Importantly, R3 KO mice suffered a more significant loss of systolic blood pressure ( $34.4 \pm 17$ vs. $20.2 \pm 19.5 \mathrm{mmHg}$ at the 6 -h time point). Although not significant, the decrease in diastolic and mean blood pressure was lower in R3 KO mice compared to the WT (Supplementary Fig. 1). In a separate cohort of mice, aortae were collected from WT and R3 KO mice $8 \mathrm{~h}$ after LPS (5 mg/ $\mathrm{kg}$ ) injections. Ex vivo wire myography showed inhibited acetylcholine-induced vasodilation in R3 KO aortic rings, suggesting LPS resulted in more severe endothelial dysfunction in the Cyb5r3 deficient endothelium (Fig. 1d). It is worth noting that the vasodilation induced by acetylcholine ex vivo depends on endothelial nitric oxide synthase (NOS3) function [35,36]. In contrast, LPS-induced vasodilation in vivo is known to be mediated by nitric oxide derived from inducible nitric oxide synthase (NOS2) in leukocytes [37, 38]. Indeed, inflammatory genes such as Nos 2 and vascular cell adhesion molecule 1 (Vcam1), but not intercellular adhesion molecule 1 (Icam1), were expressed at significantly higher levels in R3 KO mice relative to WT (Fig. 1e-g). These animal experiments indicate that CYB5R3 deficiency in endothelial cells exacerbates LPS induced inflammatory activation, endothelial dysfunction, and systemic hypotension.

To examine whether endothelial CYB5R3 deficiency is directly responsible for the enhanced LPS signaling, we challenged cultured human aortic endothelial cells (HAEC) with LPS overnight. Using $1 \mu \mathrm{g} /$ $\mathrm{ml}$ of LPS, we observed significantly higher VCAM-1 and ICAM-1 protein expression in Cyb5r3 siRNA-treated HAECs (Fig. 2a-c). It is known that a

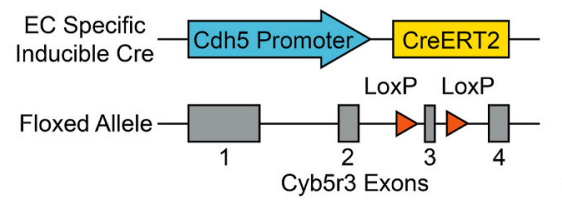

WT: Cdh5-CreERT2, Cyb5r3wtwt

R3 KO: Cdh5-CreERT2, Cyb5r3 $3^{\text {fl/f }}$

b
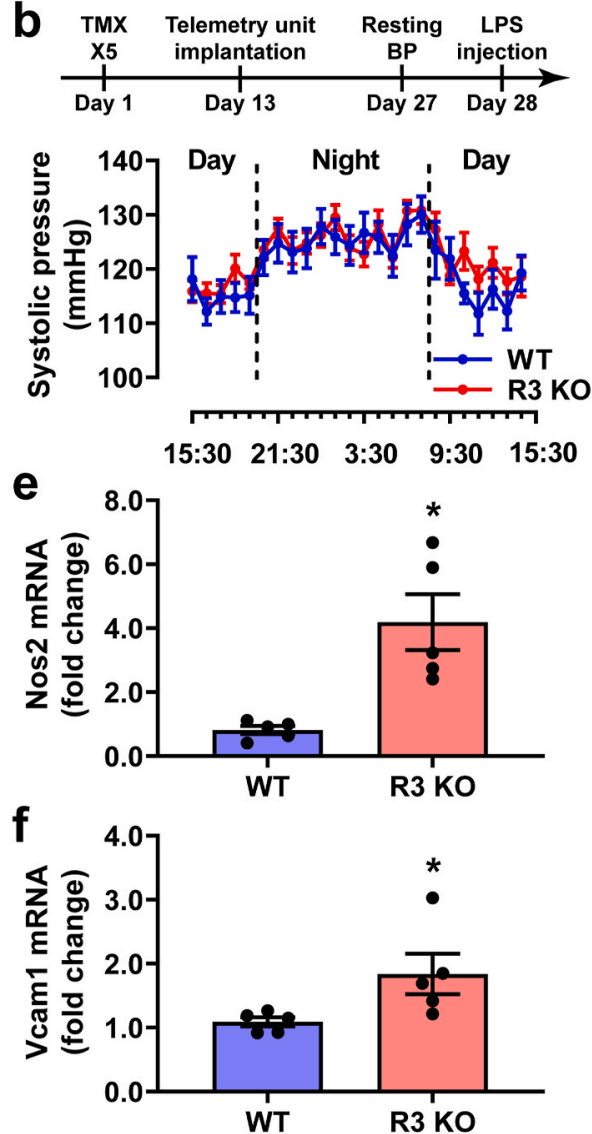

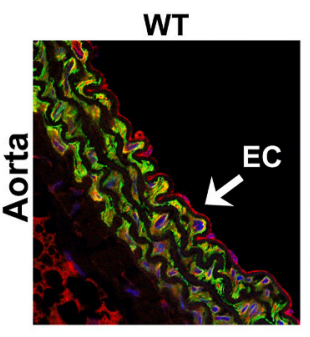

R3 KO

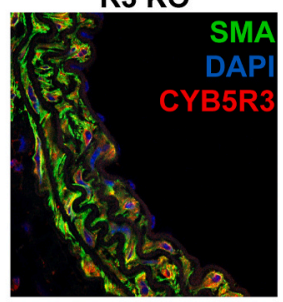

C

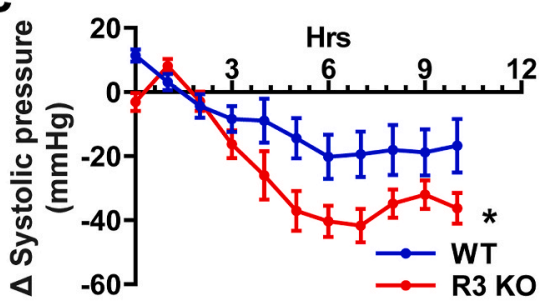

d
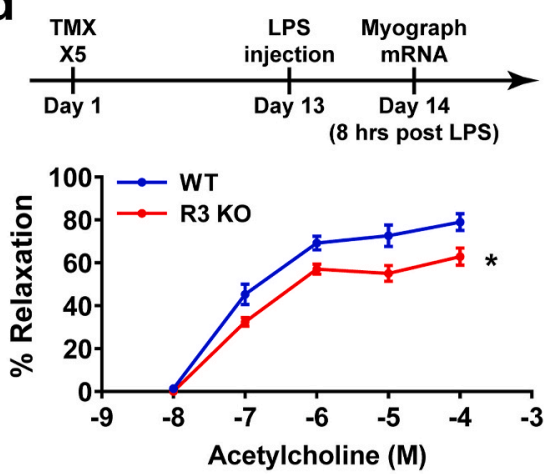

g

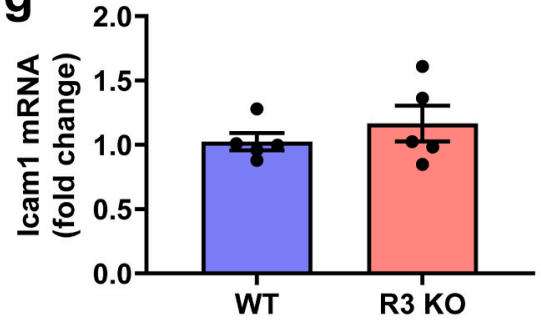

Fig. 1. LPS induced vascular dysfunction is exacerbated in endothelium-specific Cyb5r3 knockout mice. (a) Cdh5-CreER ${ }^{T 2} / C y b 5 r 3^{w t / w t}$ (WT) and Cdh5$\mathrm{CreER}^{\mathrm{T2}} / \mathrm{Cyb5} 3^{\mathrm{fl} / \mathrm{fl}}$ (R3 KO) mice were treated with tamoxifen. Endothelial CYB5R3 expression was examined by immunofluorescence staining in the aorta. (b) Mice received five daily tamoxifen $(10 \mathrm{mg} /$ $\mathrm{kg}$ ) injections and subsequent radiotelemetry unit implantation as indicated in the timeline. Systolic pressure was monitored using radiotelemetry for $24 \mathrm{~h}$ immediately before LPS treatment. $\mathrm{N}=8$ (WT) and 14 (R3 KO). (c) LPS (5 mg/kg) intraperitoneal injections stimulated hypotension in both WT and R3 KO mice. By comparing pre- and post-LPS pressures at similar times of the day, the change in systolic pressure was significantly greater in R3 KO mice relative to WT. N $=8(\mathrm{WT})$ and $14(\mathrm{R} 3 \mathrm{KO})$; * indicates $\mathrm{p}<0.05$ between WT and R3 KO with 2-way ANOVA. (d) In a different cohort, tamoxifen $(10 \mathrm{mg} / \mathrm{kg})$ treated mice were injected intraperitoneally with LPS $(5 \mathrm{mg} / \mathrm{kg})$ as indicated in the timeline. Aortae were isolated from a different cohort of mice $8 \mathrm{~h}$ after LPS ( $5 \mathrm{mg} / \mathrm{kg}$ ) intraperitoneal injections. In ex vivo wire myography, R3 KO aortae showed less vasorelaxation with cumulative doses of acetylcholine when compared to WT. $\mathrm{N}=5$; * indicates $\mathrm{p}<0.05$ with 2-way ANOVA. (e-g). The mRNA expression levels of Nos2, Vcam-1, and Icam-1 were examined in the same aorta samples. $\mathrm{N}=5$; * indicates $\mathrm{p}<0.05$ between WT and R3 KO with unpaired parametric $t$-test. 
a

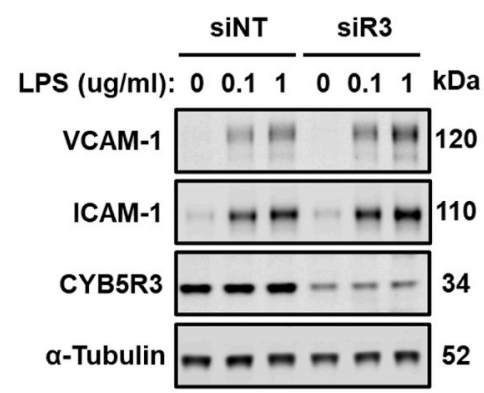

d

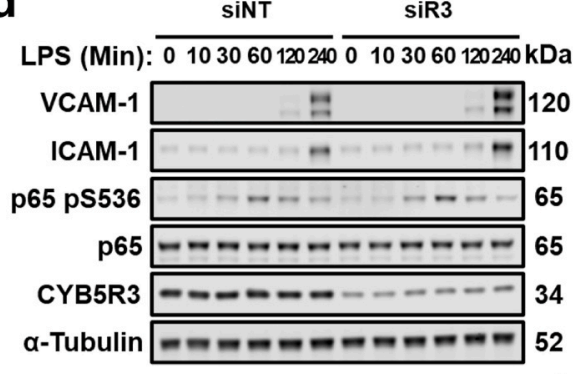

f
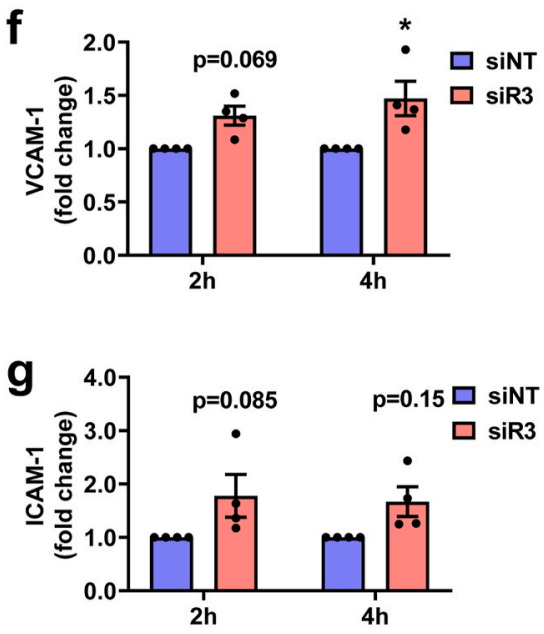

b

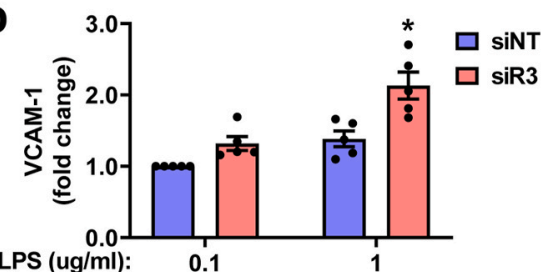

C

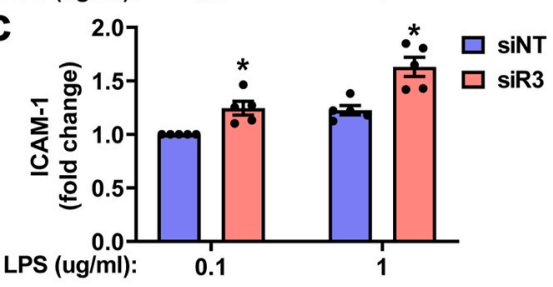

e

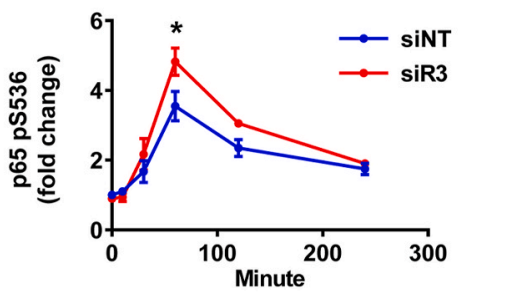

h

Fig. 2. Cyb5r3 gene silencing potentiates LPS induced NF-kB activation and VCAM-1 and ICAM1 expression in endothelial culture. HAECs were transfected with non-targeting (siNT) and Cyb5r3targeting (siR3) siRNA for $48 \mathrm{~h}$ before challenge with LPS. (a-c) HAECs were treated with 0.1 or $1 \mu \mathrm{g} / \mathrm{ml}$ LPS for $16 \mathrm{~h}$. At the $1 \mu \mathrm{g} / \mathrm{ml}$ concentration, both LPSinduce VCAM-1 and ICAM-1 protein expressions were significantly higher in the siR3 group. $\mathrm{N}=5$; * indicates $\mathrm{p}<0.05$ between siNT and siR3 with 2-way ANOVA and Sidak post-hoc test. (d-g) Cells were treated with $1 \mu \mathrm{g} / \mathrm{ml}$ LPS for up to $4 \mathrm{~h}$. VCAM- 1 was increased to a significantly higher level in siR3 treated cells relative to siNT and was accompanied by more p65 phosphorylation on S546. $\mathrm{N}=4$; * indicates $\mathrm{p}<$ 0.05 between siR3 and siNT with 2-way ANOVA and Sidak post-hoc test. (h-i) Cells were pretreated with BMS $345541(10 \mu \mathrm{M})$ for $20 \mathrm{~min}$ and challenged with LPS $(1 \mu \mathrm{g} / \mathrm{ml})$ overnight. $\mathrm{N}=3$; * indicates $\mathrm{p}<0.05$ between linked groups with 2-way ANOVA and Sidak post-hoc test.

nuclear factor kappa B (NF- $\mathrm{kB})$ is a major transcription factor responsible for VCAM-1 and ICAM-1 expression [39]. A time course of LPS treatment showed over-activation of NF- $\mathrm{KB}$ at the 1 -h time point, indicated by augmented phosphorylation of the p65 subunit and enhanced VCAM-1 and ICAM-1 expression at the 4-h time (Fig. 2d-g). Moreover, BMS 345541, an inhibitor targeting inhibitor of nuclear factor- $\mathrm{kB}$ kinase (IKK) prevented VCAM-1 and ICAM-1 upregulation in Cyb5r3 knockdown cells, indicating the overactivated inflammatory signaling was NF- $\mathrm{kB}$ dependent. Together, these data indicate that CYB5R3 is critical for LPS induced endothelial inflammatory activation both in vivo and in vitro.

\subsection{CYB5R3 mitigates LPS signaling in a NOX4 dependent manner}

It is well established that LPS signals through toll-like receptor-4 (TLR-4) to elevate ICAM and VCAM-1 expression [40]. Additionally, NOX4 has been shown to mediate LPS-TLR4 signaling in endothelial cells [41]. Considering the regulatory effect of NQO1, a CoQ reductase, on NOX4, we tested whether CYB5R3 modulates NOX4 activity to affect LPS-induced inflammatory activation using cultured HAECs treated with siRNA targeting Cyb5r3 and Nox4 mRNA, separately or in combination.
Non-targeting siRNA was added as a control for the total siRNA load. As shown in Fig. 3a, d, and 3e, both CYB5R3 and NOX4 protein expression were significantly suppressed by the corresponding siRNA. Interestingly, Nox4 siRNA slightly but significantly increased CYB5R3 protein expression (Fig. 3d), suggesting a potential compensatory effect between NOX4 and CYB5R3. More importantly, the loss of NOX4 completely prevented the upregulation of LPS-induced VCAM-1 and ICAM-1 expression in Cyb5r3 deficient HAECs (Fig. 3a-c). To examine whether the protective effects of $C y b 5 r 3$ and Nox 4 occur at the transcriptional level, we measured mRNA expression at 2 and $4 \mathrm{~h}$ after LPS treatment. Indeed, both LPS-stimulated Vcam-1 and Icam-1 mRNA were increased in Cyb5r3 knockdown HAECs at the 4-h time point (Fig. 4a and b). When HAECs were treated with Nox4 siRNA, augmentation of Vcam-1 mRNA in the Cyb5r3 deficient HAECs was ablated (Fig. 4a). By contrast, Nox4 gene silencing did not significantly affect Icam1 mRNA at either time point (Fig. 4b). It is possible that LPS-induced Vcam-1 and Icam-1 expression follow different time courses. Knockdown efficiencies of Cyb5r3 and Nox4 were verified at the mRNA level (Fig. 4c and d). Surprisingly, the compensatory upregulation of CYB5R3 protein in Nox4 knockdown cells was not significantly reflected at the mRNA level (Fig. 4c). However, Nox4 mRNA was significantly increased with Cyb5r3 
a
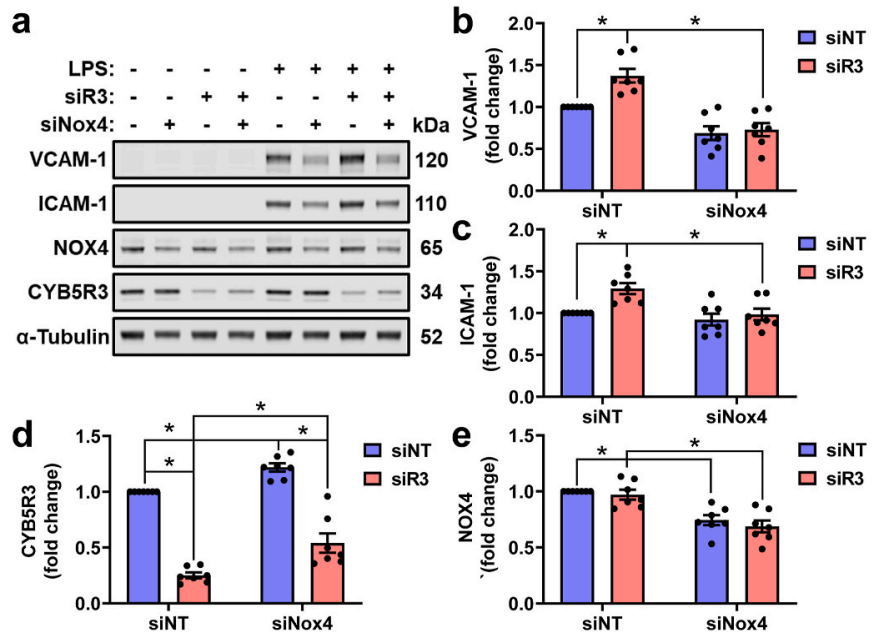

Fig. 3. The anti-inflammatory effects of CYB5R3 are NOX4 dependent. (a) HAECs were co-transfected with siRNA targeting Cyb5r3 (siR3) and Nox4 (siNox4); non-targeting siRNA (siNT) was used to keep the siRNA load the same between groups. At $48 \mathrm{~h}$ following transfection, cells were treated with $1 \mu \mathrm{g} / \mathrm{ml}$ LPS for 16 h. (b-e) Protein expression levels of VCAM-1, ICAM-1, CYB5R3, and NOX4 were quantified at the 16 -h time point. $\mathrm{N}=7$; * indicates $\mathrm{p}<0.05$ between linked groups with 2-way ANOVA and Tukey's multiple comparisons.
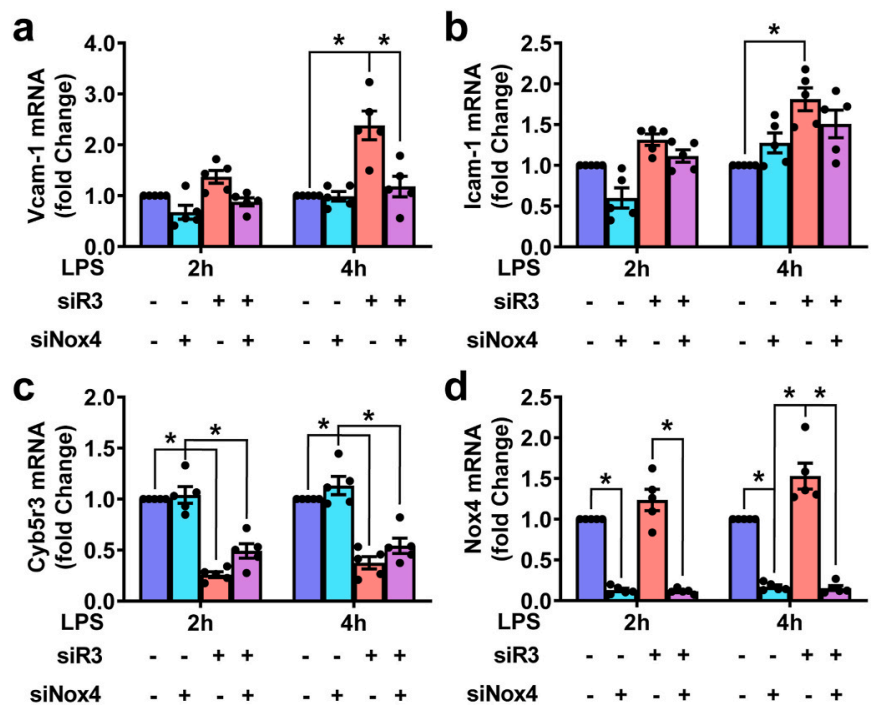

Fig. 4. NOX4 regulates Vcam1 and Icam1 expression at the transcript level. HAECs were co-transfected with siRNA targeting Cyb5r3 (siR3) and Nox4 (siNox4); non-targeting siRNA (siNT) was used to keep the siRNA load the same between groups. $48 \mathrm{~h}$ after the siRNA transfection, cells were treated with $1 \mu \mathrm{g}$ / $\mathrm{ml}$ LPS and collected 2 or $4 \mathrm{~h}$ after the LPS treatment to examine mRNA expression. $\mathrm{N}=5$; * indicates $\mathrm{p}<0.05$ between linked groups with 2-way ANOVA and Tukey's multiple comparisons.

gene silencing (Fig. 4d).

\subsection{CYB5R3 and NOX4 modulate TNF- $\alpha$ induced VCAM-1 expression}

LPS-induced inflammatory signaling in vivo can be magnified and propagated via TNF- $\alpha[42,43]$. Therefore, we extended our studies to test if the protective effects of CYB5R3 involved TNF- $\alpha$ signaling. In cultured HAECs, in which Cyb5r3 was silenced using siRNA prior to overnight treatment with TNF- $\alpha(10 \mathrm{ng} / \mathrm{ml})$, Cyb5R3 deficiency exacerbated both VCAM-1 and ICAM-1 protein expression. When Nox4 was silenced alongside Cyb5r3, only the previously seen VCAM-1 upregulation with Cyb5r3 deficiency was prevented, not ICAM-1. (Fig. 5a-c). Therefore, CYB5R3 protects, in part, against TNF- $\alpha$ mediated inflammatory signaling. Moreover, we observed the same compensatory effects on CYB5R3 and NOX4 expression (Fig. 4d and e, $5 d-e)$.

\subsection{CYB5R3 and NOX4 interact on the mitochondrial outer membrane}

Since our data indicated a protective role for CYB5R3 in LPS and TNF- $\alpha$-activated endothelial inflammation mediated by NOX4, we hypothesized that CYB5R3 may regulate NOX4 activity through ubiquinone reduction on the mitochondrial membrane. Mitochondria are a primary location for both CYB5R3 and NOX4 [11,44-46]. To test this hypothesis, we first performed immunostaining for CYB5R3 and NOX4 in cultured HAECs. Both CYB5R3 and NOX4 colocalized with TOM20, a mitochondrial marker (Fig. 6a). Their mitochondrial localization was better demonstrated by the super-resolution images stained with the same antibodies (Fig. 6b).

Moreover, we sought to determine whether CYB5R3 and NOX4 were expressed on the outer or inner mitochondrial membrane by exposing isolated mitochondria to proteinase K. As shown in Fig. 6c, CYB5R3 and NOX4 were fully digested at 10 and $3 \mu \mathrm{g} / \mathrm{ml}$ proteinase $\mathrm{K}$, respectively, which similarly occurred with the mitochondrial outer membrane protein TOM20 (Fig. 6c). In comparison, cytochrome $c$ oxidase subunit 4 (COX IV), an inner membrane protein, was resistant to proteinase $\mathrm{K}$ (30 $\mu \mathrm{g} / \mathrm{ml}$ ). These findings indicated that CYB5R3 and NOX4 reside on the mitochondrial outer membrane.

Additional studies were performed to investigate CYB5R3's spatial localization and protein-protein interactions. APEX2, a modified soybean peroxidase used to examine subcellular localization and protein interacting partners, was fused to the C-terminus of CYB5R3 (Fig. 6d) $[29,30]$. In the presence of hydrogen peroxide $\left(\mathrm{H}_{2} \mathrm{O}_{2}\right)$, CYB5R3-APEX2 converts 3,3'-Diaminobenzidine into brown precipitates that can be visualized in electron microscopy as an electron-dense signal. In HAECs overexpressing CYB5R3-APEX2, the electron-dense signal accumulated in the outer periphery of mitochondria, suggesting CYB5R3 resides on the outside of mitochondria (Fig. 6e), consistent with the long-standing hypothesis on CYB5R3's orientation on the mitochondrial outer membrane [47]. Since APEX2 can be activated by high concentrations of

a
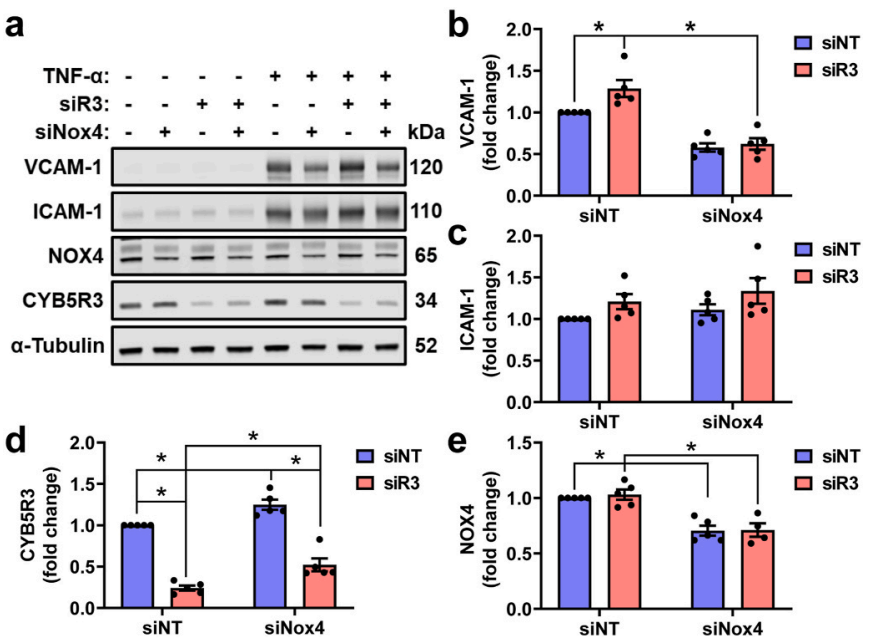

Fig. 5. Endothelial CYB5R3 and NOX4 regulate TNF- $\alpha$ induced inflammatory signaling in a similar pattern. (a) HAECs were co-transfected with non-targeting (siNT), Cyb5r3-targeting (siR3), and Nox4-targeting (siNox4) siRNA as indicated. TNF- $\alpha$ was added to the medium $48 \mathrm{~h}$ after transfection, and cells were collected after $16 \mathrm{~h}$ for immunoblotting. (b-e) Protein expression levels of VCAM-1, ICAM-1, CYB5R3, and NOX4 were quantified at the 16-h time point. $\mathrm{N}=7$; * indicates $\mathrm{p}<0.05$ between linked groups with 2-way ANOVA and Tukey's multiple comparisons. 
a
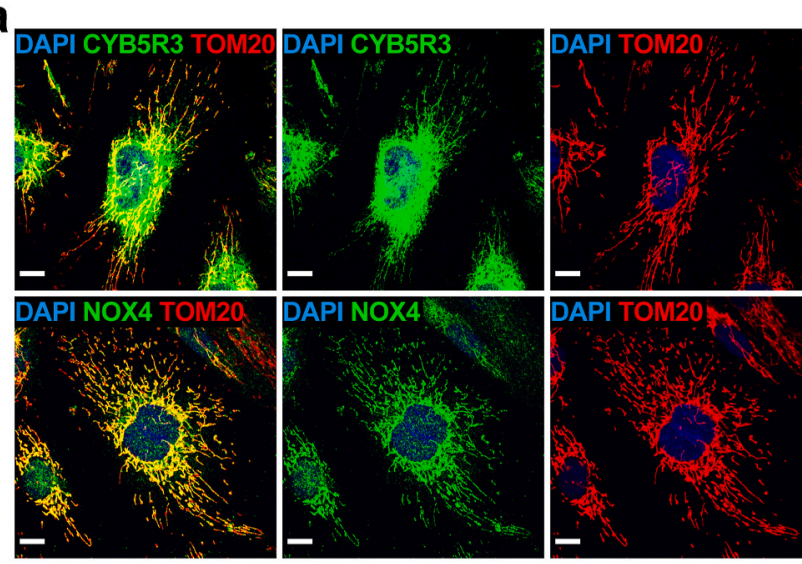

b

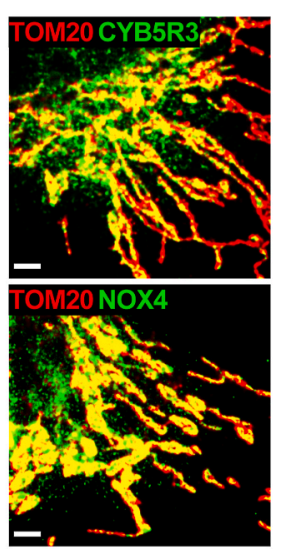

C

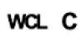

Mitochondria Proteinase K \begin{tabular}{llllllll}
\hline & 0 & 0.3 & 1 & 3 & 10301003001000
\end{tabular} (ug/ml): $\begin{array}{llllllllll}0 & 0 & 0 & 0.3 & 1 & 3 & 10 & 301003001000 & k D a\end{array}$

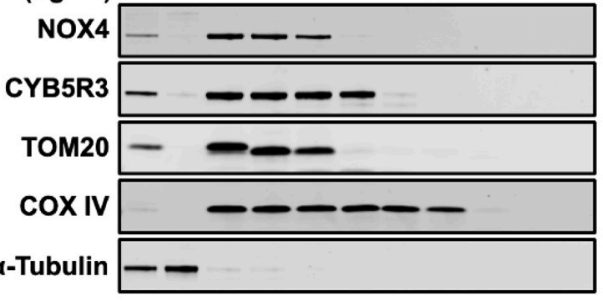

kDa
65
34
16
17
52

f
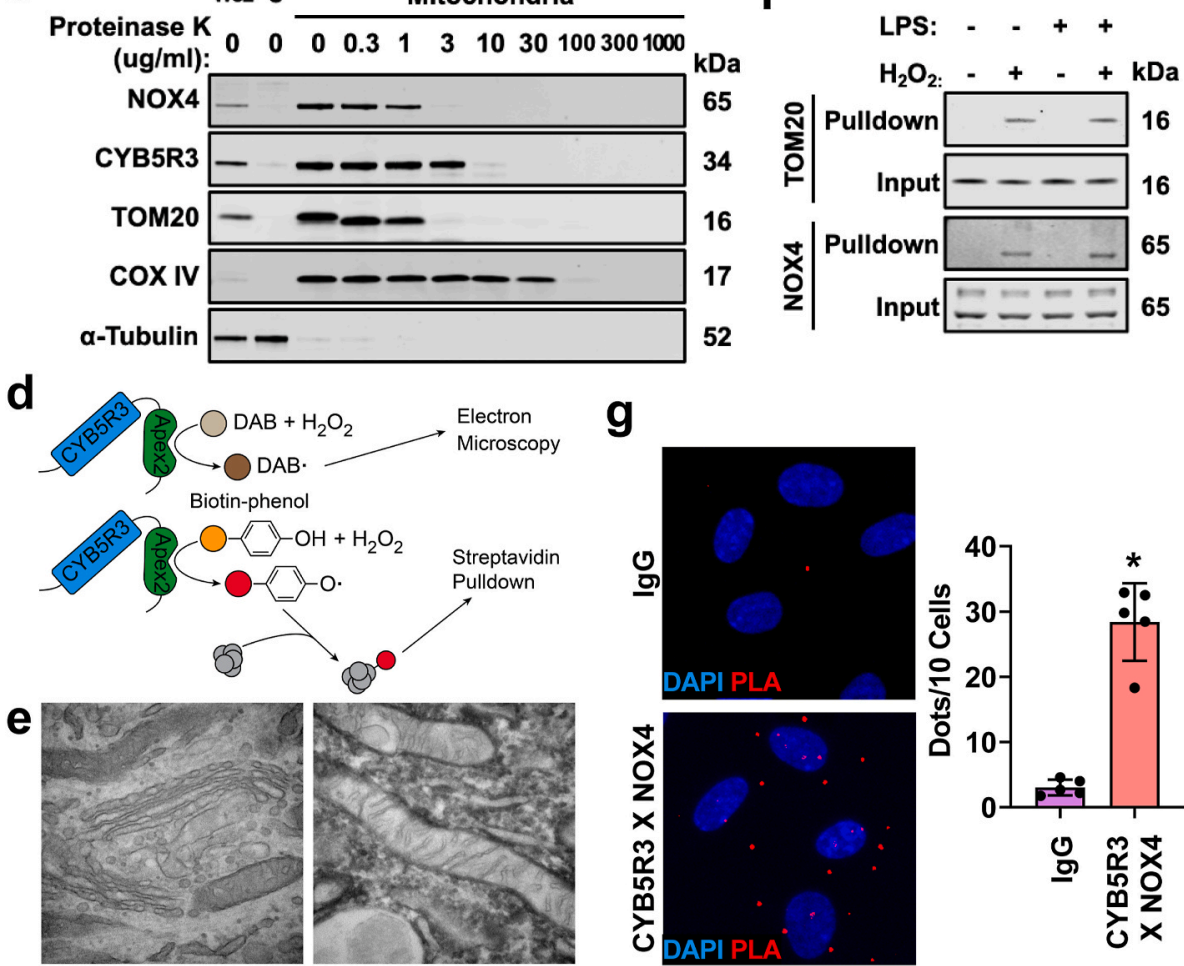

$-\mathrm{H}_{2} \mathrm{O}_{2}$

g

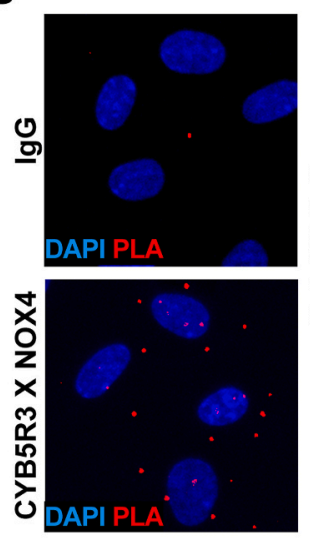

$+\mathrm{H}_{2} \mathrm{O}_{2}$

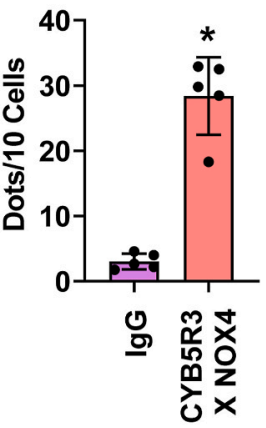

Fig. 6. CYB5R3 resides in close proximity to NOX4 in mitochondria. (a) Confluent HAECs were stained with CYB5R3 or NOX4 (green), TOM20 (red), and DAPI (blue). Both CYB5R3 and NOX4 colocalize with TOM20 in confocal images. The scale bar represents $10 \mu \mathrm{m}$. (b) The mitochondrial localization of CYB5R3 and NOX4 is shown in super-resolution images (STED). The scale bar represents $2 \mu \mathrm{m}$. (c) Mitochondria were isolated from HEK293FT cells and digested in various concentrations of proteinase $\mathrm{K}$. Proteins on the outer membrane were more susceptible to digestion compared to inner membrane proteins. (d) Strategy using CYB5R3-APEX2 to study protein subcellular localization and protein-protein interactions. (e) The electron microscopic image shows the electron-dense area around mitochondria in CYB5R3-APEX2 expressing HAECs only in the presence of $\mathrm{H}_{2} \mathrm{O}_{2}$. (f) Biotinylated proteins were captured from CYB5R3-APEX2 expressing HAECs. In the presence of $\mathrm{H}_{2} \mathrm{O}_{2}$, both TOM20 and NOX4 were detected in the pulldown samples irrespective of LPS treatment $(1 \mu \mathrm{g} / \mathrm{ml}$ for $1 \mathrm{~h})$. (g) The proximity ligation assay (PLA, red) confirmed direct interactions between CYB5R3 and NOX4 (CYB5R3 X NOX4). The PLA positive signals were quantified as dots per 10 nuclei (DAPI, blue). The quantification represents average count \pm standard deviation from 5 images in each group. * indicates $\mathrm{p}<0.05$ with Student's t-test. (For interpretation of the references to colour in this figure legend, the reader is referred to the Web version of this article.)
$\mathrm{H}_{2} \mathrm{O}_{2}$ to biotinylate proximal proteins with biotin-phenoxyl radical, we also used it to pull down biotinylated proteins from CYB5R3-APEX2 expressing HAECs. Our pulldown results included TOM20 and NOX4 (Fig. 6f), suggesting both proteins are in close proximity to CYB5R3. Proximity ligation assay was also used and revealed endogenous CYB5R3 and NOX4 to be spatially close to each other in endothelial cells (Fig. 6g).

\subsection{Membrane-bound CYB5R3 regulates NOX4 activity}

Since CYB5R3 and NOX4 reside in close proximity to each other on the mitochondrial outer membrane, we hypothesized that CYB5R3 interacts with NOX4 to regulate its activity. NOX4 is known to produce predominantly $\mathrm{H}_{2} \mathrm{O}_{2}$ and a portion of $\mathrm{O}_{2}{ }^{\bullet-12}$. HAECs treated with Cyb5r3 siRNA showed decreased $\mathrm{H}_{2} \mathrm{O}_{2}$ production and increased mitochondrial $\mathrm{O}_{2}{ }^{\bullet-}$ (Fig. $7 \mathrm{a}$ and b). Electron leakage from mitochondrial respiration is a major source of $\mathrm{O}_{2}{ }^{\circ-}$. Therefore, we examined mitochondrial function to distinguish the source of reactive oxygen species in
Cyb5r3 knockdown HAECs. The results showed that the lack of CYB5R3 did not affect protein expression levels of respiration complexes (Supplementary Fig. 2), mitochondrial respiration (Supplementary Figs. 3a-g), or mitochondrial membrane potential (Supplementary Fig. 3h) with or without LPS stimulation. Furthermore, by quantifying the superoxide specific DHE oxidation product, $2 \mathrm{OHE}^{+}$, using HPLC-MS, we confirmed increased superoxide anion levels in Cyb5r3 knockdown HAECs was NOX4 dependent (Fig. 7c). To better understand how CYB5R3 affects NOX4 activity, we created expression vectors carrying wild-type CYB5R3, inactive CYB5R3 (K111A or K111A/G180V), and non-membrane bound active CYB5R3 missing the $\mathrm{N}$-terminal membrane anchor ( $\triangle$ AA1-23). To exclude the effect of endogenous CYB5R3, we generated Cyb5r3 deficient HEK293FT cell lines using lentiviral shRNA (Supplementary Fig. 4a). CYB5R3 activity was verified in Cyb5r3 deficient HEK293FT cells forced to express similar amounts of mutant CYB5R3 (Fig. 7d). Additionally, to test NOX4 activity, Cyb5r3 deficient HEK293FT cells were co-transfected with NOX4 and its cofactor p22 (Supplementary Fig. 4b). These experiments revealed significantly 
a
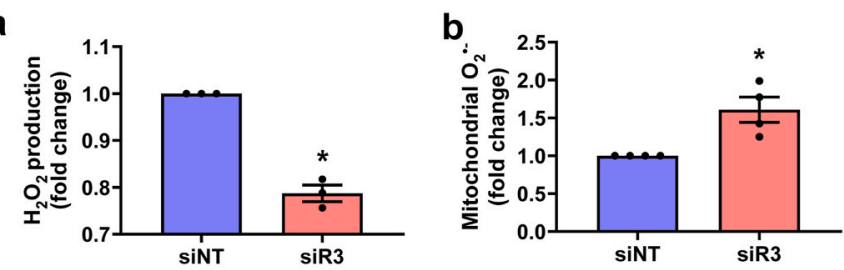

C

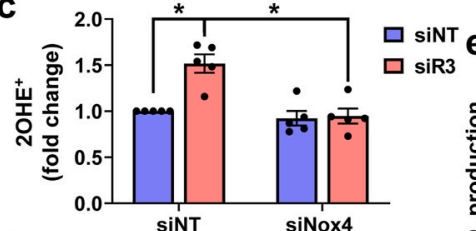

d
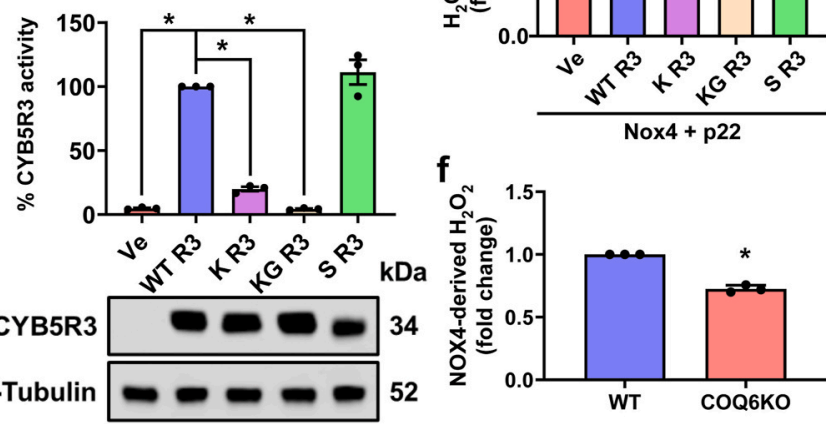

b

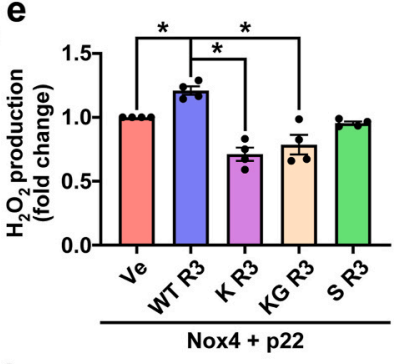

$f$
Fig. 7. Optimal NOX4 production of $\mathrm{H}_{2} \mathrm{O}_{2}$ requires CYB5R3 membrane localization and activity. (a-c) HAECs were transfected with non-targeting (siNT), Cyb5r3-targeting (siR3), and Nox4-targeting (siNox4) siRNA for $48 \mathrm{~h}$. (a-b) $\mathrm{H}_{2} \mathrm{O}_{2}$ and mitochondrial $\mathrm{O}_{2}{ }^{\bullet-}$ were measured using coumarin boronic acid and MitoSOX, respectively. $\mathrm{N}=3-4$; * indicates $\mathrm{p}<0.05$ between siNT and siR3 with ratio paired $t$-test. (c) $2 \mathrm{OHE}^{+}$was quantified with HPLC-MS. $\mathrm{N}=5$; * indicates $\mathrm{p}<0.05$ between linked groups with 2-way ANOVA and Tukey's multiple comparisons. (d) Cyb5r3 knockdown HEK293FT cells were forced to express wild-type CYB5R3 (R3 WT), K111A CYB5R3 (R3 K111A), K111A/ G180V CYB5R3 (R3 K111A/G180V), and non-membrane bound active CYB5R3 (R3 $\triangle$ AA1-23) to similar levels. CYB5R3 activities were measured with the pseudosubstrate 2,6-Dichlorophenolindophenol (DCPIP). $\mathrm{N}=3$; * indicates $\mathrm{p}<$ 0.05 between indicated groups with one-way ANOVA and Dunnett's multiple comparisons. (e) NOX4 activities were evaluated by the amount of $\mathrm{H}_{2} \mathrm{O}_{2}$ produced from NOX4 and p22 expressing HEK293FT cells. NOX4 derived $\mathrm{H}_{2} \mathrm{O}_{2}$ varied between HEK293FT cells with different forms of coexpressed CYB5R3. N $=4$; * indicates $\mathrm{p}<0.05$ between indicated groups with one-way ANOVA and Dunnett's multiple comparisons. (f) Wildtype (WT) and COQ6 knockout (COQ6KO) HEK293 cells were forced to express NOX4 and p22, and $\mathrm{H}_{2} \mathrm{O}_{2}$ production was measured. $\mathrm{N}=3$; * indicates $\mathrm{p}<0.05$ with ratio paired $t$-test.

increased $\mathrm{H}_{2} \mathrm{O}_{2}$ produced from NOX4 in cells with wild-type CYB5R3, while inhibitory effects were observed in cells transfected with inactive CYB5R3. (Fig. 7e). The activity of NOX4 did not appear to be affected in cells transfected with the non-membrane bound active CYB5R3 ( $\triangle \mathrm{AA}$ 1-23), which lacks membrane binding. (Fig. 7e). These data suggest that both the activity and membrane localization of CYB5R3 are required for NOX4 to produce $\mathrm{H}_{2} \mathrm{O}_{2}$.

\subsection{Endogenous CoQ plays a role in NOX4-dependent $\mathrm{H}_{2} \mathrm{O}_{2}$ production}

To test if the regulation of CYB5R3 on NOX4 activity is mediated by CoQ, we measured $\mathrm{H}_{2} \mathrm{O}_{2}$ generated from NOX4 in COQ6 knockout HEK293 cells unable to synthesize endogenous $\mathrm{CoQ}$ [28]. Consistent with our hypothesis, NOX4's activity to generate $\mathrm{H}_{2} \mathrm{O}_{2}$ was compromised in CoQ deficient cells (Fig. 7f). Since catalase expression was higher in the COQ6 knockout HEK293 cells than the wild-type control cells (Supplementary Figs. 5a-c), we tested whether the apparent loss of $\mathrm{H}_{2} \mathrm{O}_{2}$ production from NOX4 was due to greater $\mathrm{H}_{2} \mathrm{O}_{2}$ consumption by catalase. The use of 1,3-aminotriazole (ATZ), a catalase inhibitor, failed to increase $\mathrm{H}_{2} \mathrm{O}_{2}$ steady-state levels arising from NOX4 in COQ6 knockout cells, indicating that the compromised phenotype was most likely independent of catalase activity (Supplementary Fig. 5d). Our data confirmed that endogenous $\mathrm{CoQ}$ is required for optimal NOX4-dependent $\mathrm{H}_{2} \mathrm{O}_{2}$ production.

\section{Discussion}

Vascular wall inflammation is allied to an imbalance of reductionoxidation (redox) signaling. However, the fundamental mechanisms that modulate redox homeostasis in the setting of vascular inflammation are not fully understood. In this study, we uncover significant breakthroughs that advance the understanding of redox signaling and endothelial inflammatory activation. First, by generating a novel endothelium-specific CYB5R3 knockout mouse, we discover that knockout animals subjected to endotoxin exhibit exacerbated hypotension, endothelial cell dysfunction, and increased vascular wall inflammation, identifying a previously unrecognized role of CYB5R3 in the endothelium. Second, we discover for the first time that CYB5R3 regulates inflammation through an NADPH oxidase 4 (NOX4) -dependent mechanism to facilitate the formation of $\mathrm{H}_{2} \mathrm{O}_{2}$. Lastly, we show that mitochondrial membrane-bound CYB5R3 regulates NOX4's ability to produce hydrogen peroxide via endogenous CoQ. Collectively, these new findings highlight the functional significance of endothelial CYB5R3 in vascular wall inflammation and a previously unrecognized partnership between CYB5R3 and NOX4 via CoQ to produce $\mathrm{H}_{2} \mathrm{O}_{2}$ in order to control inflammatory signaling (Fig. 8).

NOX4 is a member of the family of NADPH oxidases that reduces $\mathrm{O}_{2}$ to reactive oxygen species. Among its family members, NOX4 is unique as it is constitutively active and generates predominantly $\mathrm{H}_{2} \mathrm{O}_{2}$. Different mechanisms have been proposed to explain NOX4's ability to produce $\mathrm{H}_{2} \mathrm{O}_{2}$ rather than $\mathrm{O}_{2}{ }^{\bullet-10,12}$. One theory is that NOX4 facilitates the dismutation of newly formed $\mathrm{O}_{2}{ }^{\bullet-}$ to $\mathrm{H}_{2} \mathrm{O}_{2}$ (Eq (1) $)^{10}$. On the plasma membrane, NOX4 is a six-transmembrane protein with both $N$ and $C$ termini in the cytosol [48]. Among NOX4's three extracellular loops, the third loop is 28 amino acids longer than the corresponding loops in NOX1 and NOX2 that are dedicated to $\mathrm{O}_{2}{ }^{\bullet-}$ production. Takac and colleagues demonstrated that NOX4, lacking the third extracellular loop or with substitution of two essential cysteines in that loop (Cys 226 and Cys270), switched to preferentially producing $\mathrm{O}_{2}{ }^{\circ-}$ versus $\mathrm{H}_{2} \mathrm{O}_{2}{ }^{10}$. The authors hypothesized that Cys226 and Cys270 may form a disulfide bond to retain a newly formed $\mathrm{O}_{2}{ }^{\circ-}$, increasing the rate of spontaneous dismutation into $\mathrm{H}_{2} \mathrm{O}_{2}$. Moreover, the authors suggested that His222 in this loop helps donate protons to the retained $\mathrm{O}_{2}{ }^{\circ}$.

Contradictory to the hypothesized intrinsic dismutase activity of NOX4, breaking the Cys226-Cys270 by $\beta$-mercaptoethanol enhanced NOX4's ability to produce $\mathrm{H}_{2} \mathrm{O}_{2}{ }^{18}$. Interestingly, NOX4 possesses a putative quinone binding site (AA203-209) that can be used to interact with CoQ. Exposing NOX4 to certain quinone compounds or NQO1, a major CoQ reductase, induced $\mathrm{H}_{2} \mathrm{O}_{2}$ production from NOX4. Furthermore, Nisimoto Y. et al. analyzed the kinetics of the $\mathrm{H}_{2} \mathrm{O}_{2}$ formation by NOX4, which did not support the intrinsic dismutase activity. Instead, their data suggested a one-electron reduction of $\mathrm{O}_{2}{ }^{\bullet-}$ to $\mathrm{H}_{2} \mathrm{O}_{2}(\mathrm{Eq}(2))^{12}$.

$2 \mathrm{O}_{2}^{\bullet-}+2 \mathrm{H}^{+} \rightarrow \mathrm{O}_{2}+\mathrm{H}_{2} \mathrm{O}_{2}$

$\mathrm{O}_{2}^{\bullet-}+2 \mathrm{H}^{+}+e^{-} \rightarrow \mathrm{H}_{2} \mathrm{O}_{2}$

In our results, endothelial cells with Cyb5r3 gene silencing had decreased $\mathrm{H}_{2} \mathrm{O}_{2}$ and increased $\mathrm{O}_{2}{ }^{\circ-}$ production (Fig. 7a and b). Since mitochondrial respiration was not affected by knocking down Cyb5r3, the elevated $\mathrm{O}_{2}{ }^{\bullet-}$ was not likely due to electron leakage from the respiratory chain (Supplementary Figs. 2-3). Indeed, simultaneously silencing Nox4 prevented $\mathrm{O}_{2}{ }^{--}$from Cyb5r3 knockdown endothelial cells (Fig. 7c). Furthermore, NOX4-derived $\mathrm{H}_{2} \mathrm{O}_{2}$ can be promoted by coexpressing the wild-type CYB5R3 but is suppressed when inactive mutants are expressed (Fig. 7e). Additionally, NOX4 activity was not affected by 


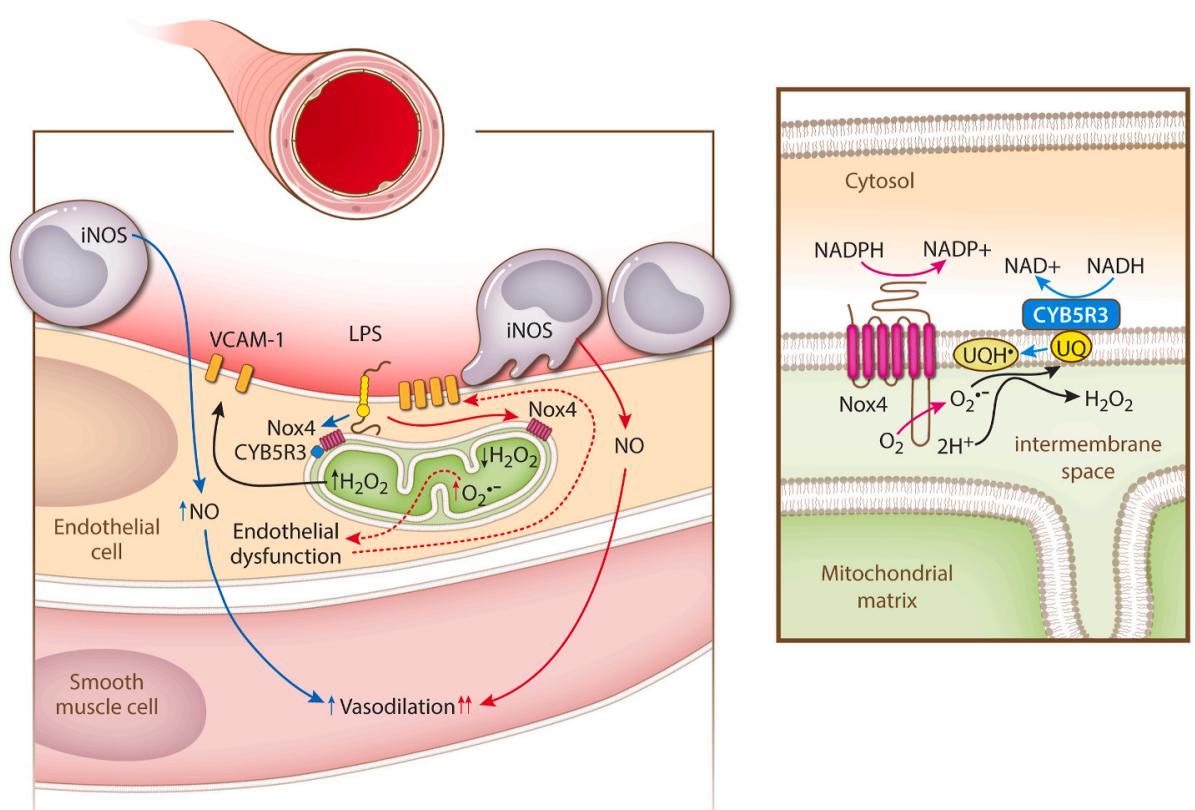

Fig. 8. Schematic for the regulation of CYB5R3 on endothelial inflammatory activation and NOX4 activity. In the right panel, CYB5R3 reduces the fully oxidized coenzyme Q, ubiquinone (UQ), to semiubiquinone ( $\mathrm{UQH}^{*}$ ) at the expense of NADH. Meanwhile, NOX4 reduces a molecule of oxygen $\left(\mathrm{O}_{2}\right)$ to superoxide $\left(\mathrm{O}_{2}{ }^{\bullet}\right)$ in the mitochondrial intermembrane space. The resultant $\mathrm{O}_{2}{ }^{\circ}$ and $\mathrm{UQH}^{\bullet}$ react to generate $\mathrm{H}_{2} \mathrm{O}_{2}$ and UQ. CYB5R3 normally facilitates NOX4 predominant production of $\mathrm{H}_{2} \mathrm{O}_{2}$ in mitochondria (left panel). During endothelial inflammatory activation, e.g., with LPS challenge, $\mathrm{H}_{2} \mathrm{O}_{2}$ derived from NOX4 upregulates VCAM-1 expression on the endothelial surface to recruit monocytes. NOS2 in recruited monocytes produces nitric oxide (NO), causing extensive vasodilation and systemic hypotension. When CYB5R3 activity is impaired in endothelial cells (right panel), NOX4 produces less $\mathrm{H}_{2} \mathrm{O}_{2}$ and more $\mathrm{O}_{2}{ }^{\circ}$, which results in elevated VCAM-1 expression, enhanced monocyte recruitment, more NOS2 derived NO, and more severe hypotension. the enzymatically active CYB5R3 missing its membrane binding capacity (Fig. 7e). These findings pointed to a crucial role for both the activity and subcellular location of CYB5R3 in the optimal function of NOX4. Therefore, we hypothesized that NOX4 generates $\mathrm{H}_{2} \mathrm{O}_{2}$ with $\mathrm{O}_{2}{ }^{\bullet-}$ reductase activity that was fulfilled at least partially in combination with CYB5R3.

In support of this hypothesis, we found that CoQ deficiency in COQ6 knockout HEK293 cells resulted in diminished $\mathrm{H}_{2} \mathrm{O}_{2}$ production from NOX4 (Fig. 7f). To our knowledge, this is the first time that endogenous CoQ has been shown to regulate NOX4 activity, which is in agreement with previous findings for synthetic quinone compounds and NQO1 overexpression [18]. Importantly, although NQO1 is known to regulate mitochondrial function, its localization on the mitochondrial membrane remains controversial [49-53]. While NQO1 can be detected in mitochondria isolated from multiple mouse tissues, it was not found in mitochondria in a human cell line [52]. This disagreement in NQO1's subcellular localization may be rooted in the difference in species, tissues, and antibody sensitivity. Nonetheless, we clearly demonstrate that CYB5R3 is enriched on the mitochondrial membrane using immunofluorescent imaging and electron microscopy in primary endothelial cells (Fig. 6a and band 6e), which is consistent with previous reports $[44,45]$. Specifically, our data indicate both NOX4 and CYB5R3 colocalize on the mitochondrial outer membrane (Fig. $6 \mathrm{c}$ and e). We further show with proximity ligation assay that NOX4 and CYB5R3 are close neighbors, permitting the two enzymes to interact (Fig. 6g). Therefore, it is possible that CYB5R3, like NQO1, reduces ubiquinone to regulate NOX4 activity.

To further understand the interaction of CYB5R3 and NOX4, the orientation of both enzymes on the mitochondrial outer membrane needs to be defined. Similar to NOX4, CYB5R3 can also be found on the plasma membrane. While the former is transmembrane, the latter a cytosolic protein anchored to the membrane by a short $\mathrm{N}$-terminal sequence [54]. Although we found that endothelial CYB5R3 and NOX4 predominantly reside on the outer mitochondrial membrane, their orientations on the plasma membrane may help with understanding their protein assembly on the mitochondrial membrane. By creating a chimeric CYB5R3 with APEX2 fused to the reductase's C-terminus, we found that CYB5R3, NOX4, and TOM20 are all in close proximity (Fig. 6f). APEX2-catalyzed biotin-phenoxyl radicals rapidly react with electron-rich amino acids on proteins in close proximity, $20-\mathrm{nm}$, because the radicals are short-lived and thus have a short radius of diffusion [55]. Since TOM20 is a transmembrane protein on the mitochondrial outer membrane, our APEX2 data indicate that CYB5R3 and NOX4 are on the outer membrane. Moreover, the biotin-phenoxyl radicals are not membrane permeable, limiting biotinylation of proteins to one side of the membrane, as shown by our electron microscopy image in which APEX2-fused CYB5R3 accumulation occurs outside mitochondria and not in cristae. Therefore, the evidence points to CYB5R3 being on the cytosolic side of the outer membrane. If we can assume that the orientation of CYB5R3 and NOX4 on the mitochondrial outer membrane is the same as on the plasma membrane, NOX4 should have both its termini in the cytosol and its "extracellular loops" in the intermembrane space (Fig. 8).

The orientation of CYB5R3 and NOX4 is crucial for their collaboration with respect to $\mathrm{O}_{2}{ }^{\bullet-}$ reduction. As a one-electron reductase, CYB5R3 reduces ubiquinone to semiubiquinone at the expense of $\mathrm{NADH}$. On the mitochondrial outer membrane, CYB5R3 is close to NOX4, allowing physical interaction between them or by association with a third player, ultimately enabling NOX4 to access semiubiquinone produced by CYB5R3. Meanwhile, NOX4 uses NADPH to produce $\mathrm{O}_{2}{ }^{\circ-}$ that is transiently trapped at the third "extracellular loop". With the electron donated by semiubiquinone and the proton donated by His222, $\mathrm{O}_{2}{ }^{--}$is reduced to $\mathrm{H}_{2} \mathrm{O}_{2}$. Furthermore, the high proton concentration in the intermembrane space, maintained by the electron transport chain, can also favor such a reaction. However, it is important to point out that the working mechanism (Fig. 8) is based on our speculation of NOX4's orientation on the mitochondrial outer membrane, which needs to be confirmed in future experiments.

$\mathrm{O}_{2}{ }^{\bullet-}$ dismutase (SOD) and reductase (SOR) represent two distinct systems for regulating $\mathrm{O}_{2}{ }^{\circ-}$ in cells. Although SORs have been found in lower organisms, their existence in mammalian cells is still under debate [56]. By contrast, three human isoforms of SODs (SOD1-3) have been identified in mammalian cells, having abundant distribution in the cytosol, mitochondria, and extracellular space. Since SOD is extremely effective at converting $\mathrm{O}_{2}{ }^{\bullet-}$ to $\mathrm{H}_{2} \mathrm{O}_{2}\left(\sim 10^{9} \mathrm{M}^{-1} \mathrm{~s}^{-1}\right)$ [57,58], an immediate question is why human endothelial cells would require an additional SOR to detoxify $\mathrm{O}_{2}{ }^{\circ-}$. A closer examination of the SOD isoform subcellular location predicates the necessity for such an alternative reductase system. On the one hand, SOD2 has a mitochondrial targeting sequence that leads it to the mitochondrial matrix [59]. On the other 
hand, SOD1 is synthesized, matured, and accumulated in the cytosol. Although there is some evidence that in yeast, SOD1 is imported to mitochondria, there is no evidence of SOD1 in mammalian cells translocating to mitochondria unless associated with neurodegenerative disorders [60]. Furthermore, we have confirmed the absence of SOD1 in isolated mitochondria (Supplementary Fig. 5a). With this current understanding of the SOD isoforms' subcellular locations, the mitochondrial intermembrane space seems to be devoid of any SOD. Since NOX4 resides on the mitochondrial outer membrane with its critical loop presumably facing the intermembrane space, $\mathrm{O}_{2}{ }^{\bullet-}$ can be trapped there and reduced to $\mathrm{H}_{2} \mathrm{O}_{2}$. It is possible that the semiubiquinone radical produced by CYB5R3, which forms on the cytosolic side of the membrane, flips across the outer mitochondrial membrane to get oxidized by intermembrane $\mathrm{O}_{2}{ }^{\bullet-}$ to form ubiquinone and $\mathrm{H}_{2} \mathrm{O}_{2}$. This "flip-flop" action of CoQ is fast enough to support a biological function such as the electron transport chain [61].

It is worth noting that NOX4 contains a cytosolic dehydrogenase domain that transfers electrons from NADPH to flavin adenine dinucleotide (FAD). The heme-containing transmembrane domain then stepwise receives one electron from the reduced and semiquinone flavin, passing it to oxygen. It has been shown that NOX4's dehydrogenase domain has a faster electron transfer rate to the downstream acceptor than other NOX isoforms [62]. This unique property may account for, in part, NOX4's preference in $\mathrm{H}_{2} \mathrm{O}_{2}$ production. While our study focused on how CYB5R3 and CoQ facilitate NOX4 in $\mathrm{H}_{2} \mathrm{O}_{2}$ production, it is not mutually exclusive with NOX4's unique mechanism in the upstream electron transfer.

The interaction between CYB5R3 and NOX4 has significant implications for endothelial inflammatory activation. In vitro, LPS induced expression of VCAM-1 and ICAM-1 was enhanced by the loss of CYB5R3 in endothelial cells on both protein and mRNA levels (Fig. 3a-c and 4ac). The overactivation of VCAM-1 and ICAM-1 by LPS in CYB5R3 deficient endothelial cells is through the NF- $\mathrm{KB}$ pathway and was completely blunted by simultaneous knockdown of NOX4 (Fig. 2h and i, 3e, and 4d). A similarly enhanced induction effect by TNF- $\alpha$ was seen for VCAM-1 (Fig. 5a and b) but not ICAM-1 (Fig. 5c). A plausible explanation is that temporal regulation of CYB5R3 on TNF- $\alpha$ induced ICAM-1 is different, which was not captured after overnight treatment. More importantly, although both Vcam-1 and Icam-1 are NF-kB target genes, it is not a surprise that they can be differentially modulated by other transcription factors and upstream signaling pathways [63,64]. The exact mechanism defining how CYB5R3 and NOX4 affect LPS and TNF- $\alpha$ induced inflammatory signaling remains a question, and future studies are needed to address specific targeting in the pathway.

As an LPS-induced cytokine, TNF- $\alpha$ contributes to the inflammatory cascade initiated by LPS in vivo $[42,43]$. To investigate this in vivo role of LPS, we created inducible endothelial cell-specific Cyb5r3 knockout mice to investigate the role of endothelial CYB5R3 in the LPS induced inflammatory cascade (Fig. 1a). Circulating LPS, as seen in sepsis, activates vascular endothelial cells to express adhesion molecules such as VCAM-1 and ICAM-1, which recruit leukocytes to the vessel. Leukocytes, such as monocytes, express NOS2 that produces nitric oxide and causes extensive vasodilation resulting in systemic hypotension (Fig. 8). We found that LPS-induced hypotension was exacerbated in mice lacking CYB5R3 in the endothelium (Fig. 1c). Although systolic, diastolic, and mean blood pressures showed the same trend that the drop of blood pressure was greater without endothelial CYB5R3, only the systolic pressure showed a significant difference (Fig. 1c and Supplementary Fig. 1). This could be due to LPS' greater impact on the systolic pressure than the diastolic pressure and the lack of statistical power in determining the effect of endothelial CYB5R3 on diastolic pressure. Moreover, without endothelial CYB5R3, aortae isolated from LPS challenged mice showed compromised acetylcholine-induced vasodilation and augmented Nos2 and Vcam-1 mRNA expression, indicating potentiated inflammatory activation and deteriorated endothelial function (Fig. 1d-f). Interestingly, endothelial Cyb5r3 deficiency did not affect
LPS induced Icam-1 transcription, which was similar to the effect of CYB5R3 on TNF- $\alpha$ signaling. Based on our previous work, $\alpha$-globin is not expressed in large artery endothelium but rather small arteries and arterioles at the myoendothelial junction and modulates endothelial NOS3-derived NO signaling [25]. Therefore, it is unlikely that $\alpha$-globin contributes to endothelial cell dysfunction in the aorta. However, we cannot rule out the possibility that $\alpha$-globin may also contribute to the hypotensive effects that may arise from the dilation of smaller resistance arteries. Future studies are needed to elucidate a likely nuanced and relative impact of endothelial CYB5R3 on the LPS signaling cascade in various segments of the vascular tree. We recognize that the increase in $\mathrm{O}_{2}{ }^{\bullet-}$ by Cyb5r3 knockdown is inconsistent with its effect in smooth muscle cells [65]. However, the seemingly incongruous results can be caused by different expression levels of NOX isoforms and cellular reliance on mitochondrial respiration for bioenergetics. Therefore, the role of CYB5R3 in redox signaling should be examined tissue by tissue.

A common confusion is on the seemingly contradictory effects of LPS in vivo and ex vivo on vasodilation. In ex vivo aorta, acetylcholine treatment activates NOS3 in endothelial cells. Endothelium-derived nitric oxide causes smooth muscle cell relaxation. Therefore, acetylcholine-induced vasodilation is endothelium-dependent and was used to determine endothelial function in the isolated aorta [35]. In comparison, NOS2 is the culprit in LPS-induced hypotension in vivo [37, 38]. LPS activates endothelial inflammatory signaling to upregulate adhesion molecules such as VCAM-1 and ICAM-1 recruiting monocytes to the vessels. Highly expressing NOS2, recruited monocytes generate a large amount of nitric oxide and cause extensive vasodilation even when the endothelium is likely damaged by the inflammatory insult (Fig. 8).

The regulation of inflammatory signaling by CYB5R3 can significantly impact the pathological progression of inflammatory disease in patients. CYB5R3 T117S, a mutant form encoded by a polymorphism (CYB5R3 c.350C $>G$ ), has a high allele frequency (23\%) in the African American population [23]. An important question is whether patients carrying CYB5R3 T117S develop more severe symptoms in infectious diseases, such as sepsis, or chronic inflammatory diseases, such as atherosclerosis. It is also worth noting that CYB5R3 is the best-defined reductase among its family members (CYB5R1-4 and CYB5RL). The endothelial cell expression levels of these proteins vary across tissues according to the Human Protein Atlas single-cell RNA seq database (RNA single cell type tissue cluster data available from https://www. proteinatlas.org). It is not clear whether other reductases may also regulate the NOX family of enzymes in the cardiovascular system.

In conclusion, by carefully examining the subcellular locations of CYB5R3 and NOX4, we determined their subcellular orientation on the mitochondrial outer membrane in primary endothelial cells. Their spatial proximity favors an interaction permitting CYB5R3-derived semiubiquinone radical to facilitate the reduction of $\mathrm{O}_{2}{ }^{\bullet-}$ generated by NOX4. This novel mechanism contributes to NOX4's ability to produce $\mathrm{H}_{2} \mathrm{O}_{2}$ rather than $\mathrm{O}_{2}{ }^{\bullet-}$. Collectively, our current work provides important and novel insight regarding the modulation of NOX4 activity that may have significant translational relevance for the management of inflammatory diseases in patients who are carriers of the CYB5R3 loss-offunction variants.

\section{Sources of funding}

This work was supported by National Institutes of Health (NIH) R01 awards [R01 HL 133864 (A.C.S), R01 HL 128304 (A.C.S), R01 HL 149825 (A.C.S), R01 HL 153532 (A.C.S), R01 GM 125944 (F.J.S.), R01 DK 112854 (F.J.S.), 1S10OD021540-01 (Center for Biologic Imaging, University of Pittsburgh), 1S10RR019003-01 (Simon Watkins (S.W.)), 1S10RR025488-01 (S.W.), 1S10RR016236-01 (S.W)]. American Heart Association (AHA) [Established Investigator Award 19EIA34770095 (A. C.S.)], Post-doctoral Fellowship 19POST34410028 (S.Y.)]. American Society of Hematology (ASH) Minority Hematology Graduate Award (A. M.D-O.). Junta de Andalucía grant BIO-177 (P.N.), the FEDER Funding 
Program from the European Union and Spanish Ministry of Science, Innovation and Universities grant RED2018-102576-T (P.N.).

\section{Author contributions}

S.Y. and A.S. conceived and designed the study. S.H., S.Y., and A.M. D-O. performed and interpreted animal experiments. S.Y., M.P.M., S.S., and Y.L. performed and interpreted cell culture, molecular biology, and biochemistry experiments. M.J.C., M.S., C.M.S, and D.S. designed, performed, and interpreted super-resolution confocal microscopy and electron microscopy. M.F. and F.J.S. designed, performed, and interpreted O2•- measurements. M.R. and S.S. designed, performed, and interpreted experiments on mitochondrial function. P.N. designed, performed, and interpreted CoQ-related experiments. E.C-P. and P.J.P. designed and interpreted NOX4-related experiments. S.Y. K.C.W., F.J.S., P.J.P., and A.C.S. wrote the manuscript, contributed to the writing, or critically reviewed the manuscript. C.M.S., D.S., P.N., S.S., F.J.S., P.J.P., and A.C.S. provided materials for the study. All authors reviewed and approved the manuscript.

\section{Declaration of competing interest}

The authors declare that they have no conflict of interest.

\section{Acknowledgment}

We thank Simon Watkins at the Center for Biologic Imaging, University of Pittsburgh, for the use of light and electron microscopes.

\section{Appendix A. Supplementary data}

Supplementary data to this article can be found online at https://doi. org/10.1016/j.redox.2021.102166.

\section{References}

[1] W.A. Muller, Leukocyte-endothelial cell interactions in the inflammatory response, Lab. Invest. 82 (2002) 521-533.

[2] A. Etzioni, Adhesion molecules-their role in health and disease, Pediatr. Res. 39 (1996) 191-198.

[3] C.G. Kevil, R.P. Patel, D.C. Bullard, Essential role of icam-1 in mediating monocyte adhesion to aortic endothelial cells, Am. J. Physiol. Cell Physiol. 281 (2001) C1442-C1447.

[4] D. Nolte, W.M. Kuebler, W.A. Muller, K.D. Wolff, K. Messmer, Attenuation of leukocyte sequestration by selective blockade of pecam-1 or vcam-1 in murine endotoxemia, Eur. Surg. Res. 36 (2004) 331-337.

[5] M. Sans, J. Panes, E. Ardite, J.I. Elizalde, Y. Arce, M. Elena, A. Palacin, J. C. Fernandez-Checa, D.C. Anderson, R. Lobb, J.M. Pique, Vcam-1 and icam-1 mediate leukocyte-endothelial cell adhesion in rat experimental colitis, Gastroenterology 116 (1999) 874-883.

[6] R.S. Hotchkiss, L.L. Moldawer, S.M. Opal, K. Reinhart, I.R. Turnbull, J.L. Vincent, Sepsis and septic shock, Nat Rev Dis Primers 2 (2016) 16045.

[7] B. Adamik, S. Zielinski, J. Smiechowicz, A. Kubler, Endotoxin elimination in patients with septic shock: an observation study, Arch. Immunol. Ther. Exp. 63 (2015) 475-483.

[8] C.N. Paiva, M.T. Bozza, Are reactive oxygen species always detrimental to pathogens? Antioxidants Redox Signal. 20 (2014) 1000-1037.

[9] S.W. Ballinger, C. Patterson, C.N. Yan, R. Doan, D.L. Burow, C.G. Young, F. M. Yakes, B. Van Houten, C.A. Ballinger, B.A. Freeman, M.S. Runge, Hydrogen peroxide- and peroxynitrite-induced mitochondrial DNA damage and dysfunction in vascular endothelial and smooth muscle cells, Circ. Res. 86 (2000) 960-966.

[10] I. Takac, K. Schroder, L. Zhang, B. Lardy, N. Anilkumar, J.D. Lambeth, A.M. Shah, F. Morel, R.P. Brandes, The e-loop is involved in hydrogen peroxide formation by the nadph oxidase nox4, J. Biol. Chem. 286 (2011) 13304-13313.

[11] A.J. Case, S. Li, U. Basu, J. Tian, M.C. Zimmerman, Mitochondrial-localized nadph oxidase 4 is a source of superoxide in angiotensin ii-stimulated neurons, Am. J. Physiol. Heart Circ. Physiol. 305 (2013) H19-H28.

[12] Y. Nisimoto, B.A. Diebold, D. Cosentino-Gomes, J.D. Lambeth, Nox4: a hydrogen peroxide-generating oxygen sensor, Biochemistry 53 (2014) 5111-5120.

[13] K. Schroder, M. Zhang, S. Benkhoff, A. Mieth, R. Pliquett, J. Kosowski, C. Kruse, P. Luedike, U.R. Michaelis, N. Weissmann, S. Dimmeler, A.M. Shah, R.P. Brandes, Nox4 is a protective reactive oxygen species generating vascular nadph oxidase, Circ. Res. 110 (2012) 1217-1225.

[14] C. Schurmann, F. Rezende, C. Kruse, Y. Yasar, O. Lowe, C. Fork, B. van de Sluis, R. Bremer, N. Weissmann, A.M. Shah, H. Jo, R.P. Brandes, K. Schroder, The nadph oxidase nox4 has anti-atherosclerotic functions, Eur. Heart J. 36 (2015) $3447-3456$.

[15] S. Basuroy, S. Bhattacharya, C.W. Leffler, H. Parfenova, Nox4 nadph oxidase mediates oxidative stress and apoptosis caused by tnf-alpha in cerebral vascular endothelial cells, Am. J. Physiol. Cell Physiol. 296 (2009) C422-C432.

[16] F. Xia, C. Wang, Y. Jin, Q. Liu, Q. Meng, K. Liu, H. Sun, Luteolin protects huvecs from tnf-alpha-induced oxidative stress and inflammation via its effects on the nox4/ros-nf-kappab and mapk pathways, J. Atherosclerosis Thromb. 21 (2014) $768-783$.

[17] A.I. Casas, E. Geuss, P.W.M. Kleikers, S. Mencl, A.M. Herrmann, I. Buendia, J. Egea, S.G. Meuth, M.G. Lopez, C. Kleinschnitz, H. Schmidt, Nox4-dependent neuronal autotoxicity and bbb breakdown explain the superior sensitivity of the brain to ischemic damage, Proc. Natl. Acad. Sci. U. S. A. 114 (2017) 12315-12320.

[18] M.V. Nguyen, B. Lardy, F. Rousset, F. Hazane-Puch, L. Zhang, C. Trocme, L. Serrander, K.H. Krause, F. Morel, Quinone compounds regulate the level of ros production by the nadph oxidase nox4, Biochem. Pharmacol. 85 (2013) 1644-1654.

[19] J.M. Villalba, P. Navas, Regulation of coenzyme q biosynthesis pathway in eukaryotes, Free Radic. Biol. Med. 165 (2021) 312-323.

[20] D.H. Hyun, S.S. Emerson, D.G. Jo, M.P. Mattson, R. de Cabo, Calorie restriction upregulates the plasma membrane redox system in brain cells and suppresses oxidative stress during aging, Proc. Natl. Acad. Sci. U. S. A. 103 (2006) 19908-19912.

[21] E. Siendones, S. SantaCruz-Calvo, A. Martin-Montalvo, M.V. Cascajo, J. Ariza, G. Lopez-Lluch, J.M. Villalba, C. Acquaviva-Bourdain, E. Roze, M. Bernier, R. de Cabo, P. Navas, Membrane-bound cyb5r3 is a common effector of nutritional and oxidative stress response through foxo3a and nrf2, Antioxidants Redox Signal. 21 (2014) 1708-1725.

[22] M. Uhlen, L. Fagerberg, B.M. Hallstrom, C. Lindskog, P. Oksvold, A. Mardinoglu, A. Sivertsson, C. Kampf, E. Sjostedt, A. Asplund, I. Olsson, K. Edlund, E. Lundberg, S. Navani, C.A. Szigyarto, J. Odeberg, D. Djureinovic, J.O. Takanen, S. Hober, T. Alm, P.H. Edqvist, H. Berling, H. Tegel, J. Mulder, J. Rockberg, P. Nilsson, J. M. Schwenk, M. Hamsten, K. von Feilitzen, M. Forsberg, L. Persson, F. Johansson, M. Zwahlen, G. von Heijne, J. Nielsen, F. Ponten, Proteomics. Tissue-based map of the human proteome, Science 347 (2015) 1260419.

[23] V.R. Gordeuk, B.N. Shah, X. Zhang, P.E. Thuma, S. Zulu, R. Moono, N.S. Reading, J. Song, Y. Zhang, M. Nouraie, A. Campbell, C.P. Minniti, S.R. Rana, D.S. Darbari, G.J. Kato, M. Niu, O.L. Castro, R. Machado, M.T. Gladwin, J.T. Prchal, The cyb5r3 (c) $(.350 \mathrm{c}>\mathrm{g})$ and g6pd a alleles modify severity of anemia in malaria and sickle cell disease, Am. J. Hematol. 95 (2020) 1269-1279.

[24] A. Martin-Montalvo, Y. Sun, A. Diaz-Ruiz, A. Ali, V. Gutierrez, H.H. Palacios, J. Curtis, E. Siendones, J. Ariza, G.A. Abulwerdi, X. Sun, A.X. Wang, K.J. Pearson, K.W. Fishbein, R.G. Spencer, M. Wang, X. Han, M. Scheibye-Knudsen, J.A. Baur, H, G. Shertzer, P. Navas, J.M. Villalba, S. Zou, M. Bernier, R. de Cabo, Cytochrome b5 reductase and the control of lipid metabolism and healthspan, NPJ Aging Mech. Dis. 2 (2016) 16006.

[25] A.C. Straub, A.W. Lohman, M. Billaud, S.R. Johnstone, S.T. Dwyer, M.Y. Lee, P. S. Bortz, A.K. Best, L. Columbus, B. Gaston, B.E. Isakson, Endothelial cell expression of haemoglobin alpha regulates nitric oxide signalling, Nature 491 (2012) 473-477.

[26] B.G. Durgin, S.A. Hahn, H.M. Schmidt, M.P. Miller, N. Hafeez, I. Mathar, D. Freitag, P. Sandner, A.C. Straub, Loss of smooth muscle cyb5r3 amplifies angiotensin iiinduced hypertension by increasing sgc heme oxidation, JCI Insight 4 (2019).

[27] Y. Wang, M. Nakayama, M.E. Pitulescu, T.S. Schmidt, M.L. Bochenek, A. Sakakibara, S. Adams, A. Davy, U. Deutsch, U. Luthi, A. Barberis, L.E. Benjamin, T. Makinen, C.D. Nobes, R.H. Adams, Ephrin-b2 controls vegf-induced angiogenesis and lymphangiogenesis, Nature 465 (2010) 483-486.

[28] M.J. Acosta Lopez, E. Trevisson, M. Canton, L. Vazquez-Fonseca, V. Morbidoni, E. Baschiera, C. Frasson, L. Pelosi, B. Rascalou, M.A. Desbats, M. Alcazar-Fabra, J. J. Rios, A. Sanchez-Garcia, G. Basso, P. Navas, F. Pierrel, G. Brea-Calvo, L. Salviati, Vanillic acid restores coenzyme q biosynthesis and atp production in human cells lacking coq6, Oxid. Med. Cell Longev. 2019 (2019) 3904905.

[29] J.D. Martell, T.J. Deerinck, S.S. Lam, M.H. Ellisman, A.Y. Ting, Electron microscopy using the genetically encoded apex 2 tag in cultured mammalian cells, Nat. Protoc. 12 (2017) 1792-1816.

[30] V. Hung, N.D. Udeshi, S.S. Lam, K.H. Loh, K.J. Cox, K. Pedram, S.A. Carr, A.Y. Ting, Spatially resolved proteomic mapping in living cells with the engineered peroxidase apex2, Nat. Protoc. 11 (2016) 456-475.

[31] H.M. Schmidt, K.C. Wood, S.E. Lewis, S.A. Hahn, X.M. Williams, B. McMahon, J. J. Baust, S. Yuan, T.N. Bachman, Y. Wang, J.Y. Oh, S. Ghosh, S.F. Ofori-Acquah, J. D. Lebensburger, R.P. Patel, J. Du, D.A. Vitturi, E.E. Kelley, A.C. Straub, Xanthine oxidase drives hemolysis and vascular malfunction in sickle cell disease, Arterioscler. Thromb. Vasc. Biol. (2020), ATVBAHA120315081.

[32] Y. Li, E. Cifuentes-Pagano, E.R. DeVallance, D.S. de Jesus, S. Sahoo, D.N. Meijles, D. Koes, C.J. Camacho, M. Ross, C. St Croix, P.J. Pagano, Nadph oxidase 2 inhibitors cpp $11 \mathrm{~g}$ and $\mathrm{cpp} 11 \mathrm{~h}$ attenuate endothelial cell inflammation \& vessel dysfunction and restore mouse hind-limb flow, Redox Biol. 22 (2019) 101143.

[33] D.S. de Jesus, E. DeVallance, Y. Li, M. Falabella, D. Guimaraes, S. Shiva, B. A. Kaufman, M.T. Gladwin, P.J. Pagano, Nox1/ref-1-mediated activation of creb promotes gremlin1-driven endothelial cell proliferation and migration, Redox Biol. 22 (2019) 101138.

[34] J. Zielonka, A. Sikora, M. Hardy, J. Joseph, B.P. Dranka, B. Kalyanaraman, Boronate probes as diagnostic tools for real time monitoring of peroxynitrite and hydroperoxides, Chem. Res. Toxicol. 25 (2012) 1793-1799. 
[35] T. Chataigneau, M. Feletou, P.L. Huang, M.C. Fishman, J. Duhault, P.M. Vanhoutte, Acetylcholine-induced relaxation in blood vessels from endothelial nitric oxide synthase knockout mice, Br. J. Pharmacol. 126 (1999) 219-226.

[36] S.D. Chauhan, G. Seggara, P.A. Vo, R.J. Macallister, A.J. Hobbs, A. Ahluwalia, Protection against lipopolysaccharide-induced endothelial dysfunction in resistance and conduit vasculature of inos knockout mice, Faseb. J. 17 (2003) $773-775$.

[37] C. Szabo, G.J. Southan, C. Thiemermann, Beneficial effects and improved survival in rodent models of septic shock with s-methylisothiourea sulfate, a potent and selective inhibitor of inducible nitric oxide synthase, Proc. Natl. Acad. Sci. U. S. A. 91 (1994) 12472-12476.

[38] A. Petros, G. Lamb, A. Leone, S. Moncada, D. Bennett, P. Vallance, Effects of a nitric oxide synthase inhibitor in humans with septic shock, Cardiovasc. Res. 28 (1994) 34-39.

[39] I. Kim, S.O. Moon, S.H. Kim, H.J. Kim, Y.S. Koh, G.Y. Koh, Vascular endothelial growth factor expression of intercellular adhesion molecule 1 (icam-1), vascular cell adhesion molecule 1 (vcam-1), and e-selectin through nuclear factor-kappa b activation in endothelial cells, J. Biol. Chem. 276 (2001) 7614-7620.

[40] F. Puhm, T. Afonyushkin, U. Resch, G. Obermayer, M. Rohde, T. Penz, M. Schuster, G. Wagner, A.F. Rendeiro, I. Melki, C. Kaun, J. Wojta, C. Bock, B. Jilma, N. Mackman, E. Boilard, C.J. Binder, Mitochondria are a subset of extracellular vesicles released by activated monocytes and induce type i ifn and tnf responses in endothelial cells, Circ. Res. 125 (2019) 43-52.

[41] H.S. Park, H.Y. Jung, E.Y. Park, J. Kim, W.J. Lee, Y.S. Bae, Cutting edge: direct interaction of tlr4 with nad(p)h oxidase 4 isozyme is essential for lipopolysaccharide-induced production of reactive oxygen species and activation of nf-kappa b, J. Immunol. 173 (2004) 3589-3593.

[42] X. Tang, D.L. Marciano, S.E. Leeman, S. Amar, Lps induces the interaction of a transcription factor, lps-induced tnf-alpha factor, and stat6(b) with effects on multiple cytokines, Proc. Natl. Acad. Sci. U. S. A. 102 (2005) 5132-5137.

[43] F. Amiot, C. Fitting, K.J. Tracey, J.M. Cavaillon, F. Dautry, Lipopolysaccharideinduced cytokine cascade and lethality in lt alpha/tnf alpha-deficient mice, Mol. Med. 3 (1997) 864-875.

[44] E.P. Neve, A. Nordling, T.B. Andersson, U. Hellman, U. Diczfalusy, I. Johansson, M. Ingelman-Sundberg, Amidoxime reductase system containing cytochrome b5 type b (cyb5b) and mosc2 is of importance for lipid synthesis in adipocyte mitochondria, J. Biol. Chem. 287 (2012) 6307-6317.

[45] R.R. Lund, R. Leth-Larsen, T.D. Caterino, M.G. Terp, J. Nissen, A.V. Laenkholm, O. N. Jensen, H.J. Ditzel, Nadh-cytochrome b5 reductase 3 promotes colonization and metastasis formation and is a prognostic marker of disease-free and overall survival in estrogen receptor-negative breast cancer, Mol. Cell. Proteomics 14 (2015) 2988-2999.

[46] K. Block, Y. Gorin, H.E. Abboud, Subcellular localization of nox4 and regulation in diabetes, Proc. Natl. Acad. Sci. U. S. A. 106 (2009) 14385-14390.

[47] A.B. Nikiforova, N.E. Saris, A.G. Kruglov, External mitochondrial nadh-dependent reductase of redox cyclers: vdac1 or cyb5r3? Free Radic. Biol. Med. 74 (2014) 74-84.

[48] K. von Lohneysen, D. Noack, M.R. Wood, J.S. Friedman, U.G. Knaus, Structural insights into nox4 and nox2: motifs involved in function and cellular localization, Mol. Cell Biol. 30 (2010) 961-975.

[49] J. Kim, S.K. Kim, H.K. Kim, M.P. Mattson, D.H. Hyun, Mitochondrial function in human neuroblastoma cells is up-regulated and protected by nqo1, a plasma membrane redox enzyme, PLoS One 8 (2013), e69030.
[50] S.M. Jaber, S.X. Ge, J.L. Milstein, J.W. VanRyzin, J. Waddell, B.M. Polster, Idebenone has distinct effects on mitochondrial respiration in cortical astrocytes compared to cortical neurons due to differential nqo1 activity, J. Neurosci. 40 (2020) 4609-4619.

[51] D. Ravasz, G. Kacso, V. Fodor, K. Horvath, V. Adam-Vizi, C. Chinopoulos, Reduction of 2-methoxy-1,4-naphtoquinone by mitochondrially-localized nqo1 yielding $\operatorname{nad}(+)$ supports substrate-level phosphorylation during respiratory inhibition, Biochim. Biophys. Acta Bioenerg. 1859 (2018) 909-924.

[52] S.L. Winski, Y. Koutalos, D.L. Bentley, D. Ross, Subcellular localization of nad(p)h: Quinone oxidoreductase 1 in human cancer cells, Cancer Res. 62 (2002) 1420-1424.

[53] H. Dong, H.G. Shertzer, M.B. Genter, F.J. Gonzalez, V. Vasiliou, C. Jefcoate, D. W. Nebert, Mitochondrial targeting of mouse nqo1 and cyp1b1 proteins, Biochem. Biophys. Res. Commun. 435 (2013) 727-732.

[54] P.G. Passon, D.E. Hultquist, Soluble cytochrome b 5 reductase from human erythrocytes, Biochim. Biophys. Acta 275 (1972) 62-73.

[55] H.W. Rhee, P. Zou, N.D. Udeshi, J.D. Martell, V.K. Mootha, S.A. Carr, A.Y. Ting, Proteomic mapping of mitochondria in living cells via spatially restricted enzymatic tagging, Science 339 (2013) 1328-1331.

[56] Y. Sheng, I.A. Abreu, D.E. Cabelli, M.J. Maroney, A.F. Miller, M. Teixeira, J. S. Valentine, Superoxide dismutases and superoxide reductases, Chem. Rev. 114 (2014) 3854-3918.

[57] J.L. Hsu, Y. Hsieh, C. Tu, D. O'Connor, H.S. Nick, D.N. Silverman, Catalytic properties of human manganese superoxide dismutase, J. Biol. Chem. 271 (1996) 17687-17691.

[58] S.L. Marklund, Human copper-containing superoxide dismutase of high molecular weight, Proc. Natl. Acad. Sci. U. S. A. 79 (1982) 7634-7638.

[59] A. Sutton, H. Khoury, C. Prip-Buus, C. Cepanec, D. Pessayre, F. Degoul, The ala16val genetic dimorphism modulates the import of human manganese superoxide dismutase into rat liver mitochondria, Pharmacogenetics 13 (2003) $145-157$.

[60] S. Abu-Hamad, J. Kahn, M.F. Leyton-Jaimes, J. Rosenblatt, A. Israelson, Misfolded sod1 accumulation and mitochondrial association contribute to the selective vulnerability of motor neurons in familial als: correlation to human disease, ACS Chem. Neurosci. 8 (2017) 2225-2234.

[61] P.B. Kingsley, G.W. Feigenson, 1h-nmr study of the location and motion of ubiquinones in perdeuterated phosphatidylcholine bilayers, Biochim. Biophys. Acta 635 (1981) 602-618.

[62] Y. Nisimoto, H.M. Jackson, H. Ogawa, T. Kawahara, J.D. Lambeth, Constitutive nadph-dependent electron transferase activity of the nox 4 dehydrogenase domain, Biochemistry 49 (2010) 2433-2442.

[63] S.D. Funk, A.C. Finney, A. Yurdagul Jr., C.B. Pattillo, A.W. Orr, Epha2 stimulates vcam-1 expression through calcium-dependent nfat1 activity, Cell. Signal. 49 (2018) 30-38.

[64] Y. Hosokawa, I. Hosokawa, K. Ozaki, H. Nakae, T. Matsuo, Cytokines differentially regulate icam-1 and vcam-1 expression on human gingival fibroblasts, Clin. Exp. Immunol. 144 (2006) 494-502.

[65] M.M. Rahaman, A.T. Nguyen, M.P. Miller, S.A. Hahn, C. Sparacino-Watkins, S. Jobbagy, N.T. Carew, N. Cantu-Medellin, K.C. Wood, C.J. Baty, F.J. Schopfer, E. E. Kelley, M.T. Gladwin, E. Martin, A.C. Straub, Cytochrome b5 reductase 3 modulates soluble guanylate cyclase redox state and cgmp signaling, Circ. Res. 121 (2017) 137-148. 